\title{
Personal Learning Environments on the Social Semantic Web
}

\author{
Editor(s): Carsten Keßler, University of Münster, Germany; Mathieu d’Aquin, The Open University, UK; Stefan Dietze, L3S Research \\ Center, Germany \\ Solicited review(s): Eleni Kaldoudi, Democritus University of Thrace, Greece; Ivana Marenzi, L3S Research Center, Germany; Fridolin Wild, \\ University, The Open University, UK; Matthew Rowe, The Open University, UK
}

Zoran Jeremića, , Jelena Jovanovića, ${ }^{\mathrm{a}, *}$ and Dragan Gašević ${ }^{\mathrm{b}}$

${ }^{\mathrm{a}} \mathrm{FOS}-$ School of Business Administration, University of Belgrade, Serbia

${ }^{\mathrm{b}}$ School of Computing and Information Systems, Athabasca University, Canada

\begin{abstract}
Today's students, being used to constant activity and multitasking in their everyday life, need a high level of social and creative engagement in order to learn; for them, highly interactive learning environments which allow for communication, collaboration, and authoring, are a must. In addition, modern learning theories stress the importance of interactivity and engagement of students for successful learning processes, whereas recent empirical studies provide evidence and confirm this. In this paper, we present how the integration of Social and Semantic Web technologies, often referred to as the Social Semantic Web (SSW), along with the Linked Data paradigm offer potentials for improving the interactivity of today's learning environments, while putting students in control of their learning process spanning across different tools and services. We identify the main principles on which such SSW-supported personal learning environments are based, and illustrate them through the design, implementation, analysis, and evaluation of DEPTHS (DEsign Patterns Teaching Help System) - a SSW-based interactive personal learning environment we have developed for the domain of software design patterns.
\end{abstract}

Keywords: Semantic Web, Social tools, Ontologies, Linked Data, Collaborative learning, Project-based learning

\section{Introduction}

Current e-learning practices are increasingly influenced by the fact that a huge number of students and teachers are members of at least one social network on the Web. In addition to being active on commonly popular social networks like Facebook, Twitter, and YouTube, many of them also actively participate in online networks specifically focused on education. For example, students typically use these educationoriented networks to share lecture notes and assignment materials with their classmates (e.g., NoteMesh $^{1}$ ). Similarly, teachers can exchange their lectures and slides on topics they present in class (e.g., SlideShare $^{2}$ and Connexions ${ }^{3}$ ). Some online social networks are aimed at connecting students and teach- ers (e.g., BuddySchool ${ }^{4}$ ). Finally, other educationoriented networks support continuous development of one's portfolios through interactions with the members of the network (e.g., Elgg ${ }^{5}$, both as a social network and social software platform).

The acceptance of social networking tools (and the broader category of social software tools) in education is primarily led by teachers enthusiasts who, trying to make their classes more engaging for students, turn to these popular online tools and make them part of their, often innovative, teaching practices. However, since evidence is still lacking as to whether and to what extent these tools are beneficial for education, different authors have different views on their usefulness in educational settings. Besides individual practitioners, the growing number of re-

*Corresponding author. E-mail: jeljov@gmail.com 
searchers (e.g., [1,2,3]) and research projects (e.g., iCamp $^{6}$ and Horizon Project ${ }^{7}$ ) in technologyenhanced learning have been exploring the potentials of these tools and reporting the benefits of and challenges for their broader application. Some even consider that further development of social networking tools and Web in general can provide technical grounds for much needed disruptive innovations in education [4]. On the other hand, there are authors who are skeptical about these tools and their educational potentials (e.g., [5, 6]). Having done a deep exploration of the educational potentials of social software tools (as presented in the following sections), we believe that it is reasonable to expect that these tools will be increasingly present in educational practices. Accordingly, we follow such a perspective in our own exploration of this field.

To realize their full potential in the educational domain (as well as in many other domains), today's social networks have to evolve. Currently, these networks are like isolated islands - knowledge and learning resources can be exchanged within the island (i.e., the network) but not across multiple islands, at least not without a lot of manual copy-and-paste effort. For example, consider a student learning about a certain domain topic and trying to consult related resources gathered by an expert or his/her peers. The resources maintained by these people may be located on many different online social networks, and cannot be automatically imported in the student's current learning environment and context (e.g., described by her learning activities and goals). This is the challenge that the Data Portability ${ }^{8}$ movement is aiming to address on the Social Web in general (i.e., not exclusively related to learning and education), by providing users with means to easily move their data across different Social Web applications.

However, content and human discovery is not the only important issue for an effective learning environment. Modern learning theories stress the importance of interactivity [7] and engagement of students [8] for successful learning processes, whereas recent empirical studies provide evidence and confirm this (see Section 2.4 for some background). Yet, widely used (e-)learning environments (e.g., Learning Management Systems) do not support students' interactivity across diverse learning systems, tools, and online educational networks that students turn to during the learning process. Even though some of them do support widely accepted online interaction paradigms and practices (such as bookmarking, tagging, commenting, and communicating via short messages), those interactions are confined to the "walls" of the learning environment.

Recognizing the weaknesses of the present social software and interactive learning environments, the e-learning community has come up with and already widely embraced the concept of Personal Learning Environments (PLEs) [9]. PLEs let the learners control their learning environment while promoting interactive learning in distributed web contexts. As Section 2 demonstrates, there has been a considerable amount of research and development related to PLEs. Still, the problem of personalized and meaningful integration of distributed learning data/systems facilitating pedagogically sound interactive learning is an open research challenge. Moreover, there are no widely adopted principles that can provide developers with a set of systematic guidelines for building PLEs.

To address the above two open challenges of PLEs, this paper proposes a set of principles for designing PLEs based on both the Social Semantic Web (SSW) and Linked Data paradigms. SSW has emerged recently as a new paradigm for creating, managing and sharing information on the Web [10]. It is based on the idea of merging the best features of Social Web and Semantic Web, through combining the common formats for defining and structuring information with the social mechanisms for creating and sharing the knowledge. We argue that by using SSW technologies and following Linked Data paradigm and principles [11], "walled garden” learning environments can be turned into open, interactive PLEs. To allow for a systematic development of such environment, we recommend a set of development principles (Section 3). By following these principles, we developed a PLE that allows for project-based and collaborative learning of software design patterns (Section 4). The implemented PLE enabled us to thoroughly analyze the recommended principles (Section 5) and evaluate the effectiveness of the approach in a real learning setting (Section 6).

\section{Social Semantic Web and Interactive PLEs - State of the Art}

In this section, we give a brief literature overview of the research areas relevant for our work - Social Semantic Web, Personal Learning Environments and Interactivity in Learning - aiming to present the state-of-the-art in these areas and thus set the stage for the principles for designing interactive PLEs which we propose in the next section (Section 3). 


\subsection{Social Semantic Web in e-learning}

The Social Semantic Web (SSW) stands for a new paradigm for creating, managing and sharing information through combining the technologies and approaches from the Semantic Web and the Social Web (Web 2.0). The former aims at giving information a "well-defined meaning, better enabling computers and people to work in cooperation” [12] through the definition of ontologies [13]. The latter is a platform for social and collaborative exchange [14] where users meet, collaborate, interact and most importantly create content and share knowledge through, e.g., wikis, blogs, photo- and video sharing services. SSW emerged by merging the best of these two worlds, through combining the common formats for defining and structuring information with the social mechanisms for creating and sharing knowledge [10]. On SSW, socially created and shared knowledge leads to the creation of explicit and semantically-rich knowledge representations [15]. This novel paradigm has already started making its way into e-learning and education, as shown, e.g., in [16] and [17]. Specifically, SSW has already shown as beneficial for: i) on-demand assembly of course content from existing learning objects [18]; ii) learning and knowledge sharing in collaborative e-learning environments $[19,20,21,22]$; and iii) provision of highly informative feedback for educators [23]. Below we present how it has been leveraged for the realization of PLEs, and further on in the paper (see Section 4.3) how it enabled us to develop advanced, context-aware educational services that support and foster interactivity in a PLE.

\subsection{PLEs - a common denominator of modern e- learning approaches}

Different authors provide somewhat different definitions of PLEs. However, common features of these learning environments did emerge and include (but are not restricted to) the following :

- Facilitate online interaction: interaction with content and interaction with other individuals around the shared content;

- Put the control over the learning process in the hands of learners;

- Bring together all the disparate resources of the learner's interests and simplify their management;
- Allow for creating new meaning through interaction with (annotation, linking and aggregation) disparate existing resources.

Accordingly, a PLE can be considered as a facility for an individual to access, combine, configure and manage digital resources (content and services) related to their present learning needs and interests. In addition, it provides means for seamless communication and collaboration among individuals involved in a learning process. PLEs are often associated with informal learning, but are also entering the formal learning scene mostly through the efforts of PLE researchers who are also educational practitioners (i.e., teachers) ${ }^{10}$.

The notion of PLE recognizes the importance of interaction for learning - interaction with content as well as social interaction with members of a learning community or/and the Web in general. In order not to alienate learning interactions from those that today's students are well accustomed to, most PLEs adopt the widely accepted online interaction paradigms and practices, such as bookmarking, tagging, commenting, communicating via short messages, status updating, and the like.

Related to the notion of PLE is the metaphor of "Teacher as DJ"11, introduced by Wiley in 2005. This metaphor has recently been revitalized and even put into practice under the name "Open Educator as a DJ"12. It demonstrates how different kinds of Social Web tools can be applied (by teachers) over open, publicly accessible (learning) content to produce new, contextualized teaching/learning content. However, this metaphor and practice can be further generalized so that not only teachers are the ones who do content sampling, (re-)mixing and presentation, but also learners can and should perform these activities as a part of their learning process.

Wild et al.'s view on PLEs, presented in [24], somewhat differs from the 'mainstream' view presented above. They consider learning environments, their construction and maintenance as the crucial parts of both the learning process and the expected learning outcome. Accordingly, the learning environment is not a stage where the learning activities are taking place, but it is something that is created during the learning process and is considered as its most crucial result. The notion of learning environment is also extended to include not only tools, but also artifacts, and different actors involved in the learning process (learners, teachers, and experts). This novel perspective on learning environments is accompanied by a novel approach to learning envi- 
ronment design which is technically supported by a domain-specific language allowing learners to easily construct and maintain their PLEs. This approach can be considered a part of the broader area of end-user development.

\subsection{Educational Mashups: the Materialization of PLES}

From a technical point of view, a PLE can be viewed as a self-defined collection of services, tools, and devices that help learners build their Personal Knowledge Networks, encompassing different kinds of learning resources (content, services, people) [25]. Sire et al [26] proposed a model for estimating the quality of different web platforms with respect to the technical support they provide for PLEs. The model consists of six dimensions: screen, data, temporal, social, activity and runtime; each dimension is further defined through a set of four features (e.g., the data dimension includes the following features: interwidget communication, drag and drop, PLE data manager, and Linked Data support). As explicitly stated by the authors, a PLE does not need to support any of these dimensions and it is fine as long as that PLE is aimed to be used for one specific learning design and learning settings for which it has been developed. However, if a PLE is to be generic, that is, capable of supporting different learning scenarios and learning contexts, it should support as many of these dimensions as possible. The model proposed by Sire et al. is highly related to the Principles we suggested in this paper (Sect. 3). However, whereas this model is focused on technical and implementation aspects of PLEs, the proposed Principles are more general in nature and besides technical aspects, also cater for pedagogical elements of PLEs (e.g., interactivity and self-regulation in learning).

Since most often PLEs are realized through combination of various Web 2.0 sources, they are also called Mash-Up Personal Learning Environments or MUPPLEs [24]. There are two types of MUPPLEs:

- Mashups by aggregation: most of the state- ofthe-art mashup PLE solutions fall into this category; these mashups mainly support learners in putting together content from different sources (mainly feeds and widgets) into a single interface. Personal dashboards, like iGoogle, NetVibes and PageFlake are typical examples.

- Mashups by integration: allow for combining data from different sources and exchanging data among the tools and services integrated into the
PLE; the integrated data can serve as an excellent basis for adaptation and personalization of PLEs through the provision of advanced context-aware services [27]; however, mashups of this type (still) require programming skills and thus have not been that widely accepted among end users (learners and teachers).

Since our research work, as well as the work of the MUPPLE research community in general, is primarily focused on the MUPPLEs of the latter type, in what follows we present different approaches to their implementation, categorized based on the major technology they rely upon. However, as some of the presented solutions combine two or more technologies, we classify these based on the technology that we perceived as dominant for the particular solution.

\subsubsection{PLEs based on Web 2.0 APIs}

Most of the proposed mashup PLE approaches fall into this category. Common features of these approaches include [25]: (1) pulling data from external (RSS or Atom) feeds, (2) filtering, sorting, and combining many feeds into one, (3) exporting results as RSS, JSON, XML, and other formats, and (4) creating a widget for seamless integration of the results in other Web sites.

PLEM [28] is a mashup driven aggregator and filter of diverse kinds of learning resources (e.g., learning content, activities, experts, communities). Inspired by the aforementioned David Wiley's concept of "the learner as DJ", PLEM allows one to create a personalized space, where she/he can easily aggregate, manage, tag, rate, and share learning resources of interest. Learning resources are made accessible through social media APIs that allow for the access to and retrieval of open educational resources (via MIT OCW ${ }^{13}$ and OUNL OpenER ${ }^{14}$ ), blogposts (via Google Blog Search and Technorati), videos (via Google Blog Search and YouTube), books (via Google Book Search), images (via Google Image Search and Flickr), and presentations (via Slideshare). PLEM harness the collective intelligence of its users to provide them with a mechanism for ranking and recommending learning resources. Specifically, users' actions, such as commenting, saving, liking, rating, viewing, and sharing, are considered as votes for respective learning resources and are used for ranking and recommendation purposes.

As previously mentioned, Wild et al [24] suggested a novel approach to learning environment design in which learners empowered by a domain- 
specific language (Learner Interaction Scripting Language - LISL) construct and manage their PLEs. Their prototypical implementation, called MUPPLE (Mash-UP Personal Learning Environment), allows for the reuse of different existing tools and their presentation to the user (learner) in an integrated manner (like personal dashboards). The communication is achieved through feeds and connect statements which establish the feed channels between the tools [29].

ReMashed is a system that recommends learning content by using the collective intelligence emerging in a PLE [30]. The PLE is realized through the aggregation of popular Web2.0 services, such as Flickr and Delicious. ReMashed uses collaborative filtering to offer recommendations; it matches together learners with similar opinions about learning resources. Ratings and tags of like-minded users are used to create personalized recommendations for the current learner.

Graasp [31] is an online learning environment that allows users to aggregate data and content from different social media and social networking applications. It has in-built support for some popular content types (e.g., videos, books and slides) and their providers on the Social Web (such as YouTube, SlideShare and Amazon); in addition, the application can be extended to include other content types and other social media applications. Graasp also allows users to communicate and collaborate not only within the system boundaries, but also with peers who are using some external communication or collaboration application; this is supported through the use of widgets.

\subsubsection{PLEs based on Social Semantic Web and Linked Data paradigm}

Talis Aspire ${ }^{15}$ is aimed at enhancing the process of authoring resource lists by allowing users to easily discover appropriate content that can be re-used and remixed [32]. In addition, by harnessing the existing work it can provide recommendations to authors of new lists within comparable subject areas. Recommendations are primarily based on the identified patterns of resource usage (e.g., which resources were often used together, or whose contributions were most often re-used). In addition, students votes for resources, both explicit (e.g., ratings and stated intensions regarding resource usage) and implicit (e.g., number of accesses and downloads of a particular resource), are also used as a valuable source of data for generating recommendations. The Talis Aspire system is completely based on Linked Data princi- ples and makes use of several ontologies to fully semantically describe the resources so that they can be easily combined and remixed. Even though this system cannot be considered a typical PLE, its features related to pulling content from different sources, reusing and remixing the content, and allowing for seamless collection of users' (learners') feedback do fit into the "Teacher as a DJ" metaphor.

The GroupMe! ${ }^{16}$ system combines Web 2.0 and Semantic Web technologies to provide personalized content management in a group (social networking) context [33]. Hence, it can be considered as a PLE of a specific group of learners, often gathered around the same learning objective. From the Web 2.0 side, it leverages intuitive user interfaces that allow users to create groups of resources (Web pages, videos, images). Creation of groups, addition of resources to the groups, and any other operation related to the groups are all saved as RDF triples compliant to a set of ontologies that GroupMe! uses. By leveraging Semantic Web technologies for storing data about group-related (content and knowledge management) activities, GroupMe! allows for the integration, sharing and better (re-)use of resources relevant for a group of users. In particular, this eliminates the problems of ambiguity and improves the ranking of the discovered resources.

The GroupMe! system served as a technical foundation for the development of LearnWeb2.0, a learning environment for Content and Language Integrated Learning [34]. LearnWeb2.0 supports a collaborative group search and syndication of resources from a number of Web 2.0 services, such as YouTube, SlideShare, and Blogger. It provides: 1) a personal space offering access to resources from various Web 2.0 repositories; 2) collaborative aggregation of collected resources; 3) sharing of the so-called 'standing queries', where users are notified whenever a new learning resource matches the query; and 4) integration of the user's social networks from different Web 2.0 services.

The Ensemble project ${ }^{17}$ is exploring the potential of semantic technologies to support and enhance teaching and learning in higher education, with special focus on learning settings where some kind of case based learning is the pedagogy of choice. The adopted research approach assumes the combined usage of digital repositories, Semantic Web technologies, and features of 'social software' in order to allow for reuse through reconfiguration, adaptation, and collective action. This implies that the project is following SSW paradigm in building learning environments that bear a lot of resemblance to PLEs. 


\subsubsection{PLEs realized on SOA principles}

Chatti et al. [25] proposed a mashup PLE framework, called PLEF-Ext, which allows for mashing-up RESTful services and makes use of semantic approaches to deal with service integration and mediation within mashup PLEs. Specifically, PLEF-Ext leverages semantic description of learning services, expressed using Service Mapping Description language, to enable finding, sharing, integrating, managing, reusing, and remixing the services with minimum effort.

\subsection{Interactivity in e-Learning}

Interactivity in e-learning assumes learners' active participation in the learning process, rather than passive consumption of the content server by instructors [35]. It implies 'doing' as opposed to 'being' (present) [36], and could be equated with social and creative engagement, that is, communication, collaboration and authoring.

Today's students and teachers are citizens of the Social Web where the notions of social interaction, human computing, and collective intelligence are major assets. They are well accustomed to interaction paradigms and practices of Social Web, such as bookmarking, tagging, commenting, communicating via short messages, status updating, and the like. Accordingly, in order to be broadly accepted by students and teachers, the solutions for enhancing the interactivity in e-learning should be based on these already widely accepted forms of interaction which are currently (in everyday life) well supported by diverse kinds of social software tools. However, we believe and have already shown [16] that the integration of Social and Semantic Web technologies has potential to offer even a better solution. Specifically, in our previous work [16], we have explored the potential of the SSW paradigm for improving present and developing new forms of interaction along each dimension of the "interactivity triangle" [37]. Our research work has been grounded on the "interactivity triangle" since it is a widely accepted model of interactivity in learning settings which has students, teachers and content at its vertices, and where each vertex is related with the other two and with itself (so that, for example, students are in interactions with teachers and content, but they also interact among themselves). We have indicated the potential of the SSW paradigm for: i) introducing new and improving existing forms of Interaction; ii) supporting interactivity across different systems and tools; and iii) integrating interaction data to allow for advanced forms of adaptation and personalization in e-learning [38].

\section{5. (Semantic) Social Software Tools in e-Learning: State of the Practice}

We have conducted a small-scale study in order to investigate the tools and services that leverage the Social Web and/or SSW paradigm for educational purposes, and get a better understanding of what kinds of tools/services have actually been used in practice and to what extent. The ultimate aim of the study was to find out whether and to what extent the tools that are currently in use could actually be employed for the realization of interactive PLEs.

The applied methodology included three primary steps: 1) identification of potentially relevant tools ${ }^{18}$, 2) analysis of candidate tools with respect to a predefined set of criteria, and 3) selection of representative tools. Since social software tools and their semantically enhanced counterparts differ with respect to the underlying technology and the general level of maturity, we had to apply somewhat different approaches when reviewing and analyzing the tools from these two categories. To keep the narration clear and avoid any potential ambiguity, in the rest of the paper we refer to the former category of tools as social software tools and the later as SSW tools.

To select potentially relevant tools, we made use of both scholarly publications (i.e., journal, conference, and workshop papers), and Web content (content of, e.g., blogs, wikis, and discussion forums) generated by learning professionals worldwide. The latter source, even though less formal, is continually growing in both quantity and relevancy and offered us with great insights into educators real-world experiences with diverse Web-based tools. We also explored published surveys (e.g. SemTech Survey ${ }^{19}$ and [17]), tools listings (e.g., Sweet Tools ${ }^{20}$ ) and ratings (e.g., The 100 Tools for Learning ${ }^{21}$ ) of Webbased tools used for learning purposes.

The common criteria we used for the analysis of both kinds of tools are: 1 ) the ability to support, or even foster, interaction within an online community; and 2) the tool's applicability for educational purposes. Our choice to focus on interactivity of the considered tools was motivated by the fact that (as explained above) interaction is one of the key characteristics of the PLE concept; additionally, its pedagogical value is stressed by the major modern learning theories [16]. The criterion related to interactivity was further narrowed down to: interactions among 
members of an online learning community, and interactions with learning content. An additional third criterion, defined only for SSW tools, was the use of Semantic Web technologies for achieving advanced functionalities.

Even though social software tools have not yet become part of educational technology mainstream, they have reached a high level of maturity and have been increasingly adopted in educational practices worldwide. On the other hand, SSW tools are still quite immature and there is a scarce evidence of their application in real-world educational settings. Therefore, we had to use different approaches when eliciting representative tools of these two categories of tools. The social software tools were chosen based on the documented experience of their usage in learning settings, as well as their ratings in the previous studies. For example, the yearly report on the 100 Tools for Learning produced by Centre for Learning and Performance Technologies ${ }^{22}$ provides practitioners' (i.e. teachers') perceptions of and opinions about each tool included in the list. Likewise, interviews and panel discussions with educational professionals and practitioners ${ }^{23}$ provide insight into their experience with different social software technologies and tools. For the other category of tools - SSW tools we present all the tools we identified that 'passed' the first (support for interactivity) and the third (advanced functionalities achieved through the use of Semantic Web technologies) criteria of the analysis phase. We did not strictly consider their successful application in educational settings (as the evidence of their usage is generally lacking), but considered their potential for use in education (mainly based on their features).

Our results are summarized in Table 1, given in Appendix, where we present the selected representative sets of both social software tools and SSW tools. Both kinds of tools are grouped into two broad categories based on the kind of interaction they (primarily) support: 1) interaction among members of an online learning community; and 2) interaction with (learning) content. Each of these categories is further narrowed down into subcategories reflecting the primary functionality offered by the tools within that subcategory (e.g., social networking, collaborative authoring, etc). It is important to stress that this is not a strict classification of tools since a significant number of them could be placed into more than one of these subcategories.

\section{Principles}

Having analyzed the state-of-the-art in the domains of PLEs and (support for) interactivity in elearning, as well as the state-of-the-practice in the application of social software and SSW tools in elearning, we set ourselves on the task of identifying the requirements for the realization of interactive PLEs. We looked into the requirements originating from: i) the concept of PLE; ii) the concept of interactivity in e-learning; iii) the identified strengths and weaknesses of the existing PLE implementations; and iv) the general trends in web-based (social) interactions and education, which includes, e.g., the use of numerous distributed and heterogeneous webbased applications, huge quantities of available content that is increasingly difficult to deal with, interactions with peers around the shared content, trust in the peers' recommendations, etc. Having analyzed these requirements we came up with a set of principles that could serve as a reference when developing software architecture of an interactive PLE. We present these principles in Table 1 and give below the rationale for each one of them. The principles are highly mutually connected and reinforced; some of them, e.g., Principle 7, depend on other principles for their successful realization. Please note that the number associated with each principle is not aimed at indicating its relevancy.

\subsection{Principle 1: Integration}

The need for a PLE is based on the fact that learning is increasingly occurring in different places and situations and is not necessarily tied to one institution (e.g., school, university) [9]. Accordingly, one of the basic premises of the PLE concept is the ability to integrate resources from disparate software tools and services that individuals use in their daily learning practices. However, data integration across different applications is still a challenge given that a great majority of applications makes use of a bespoke schema for the data representation and storage. As discussed in the previous section (see Section 2.3), the research community is trying to address this problem by suggesting different approaches and technical solutions for realizing mashups of content and data originating from different tools/services an individual makes use of. The most advanced solutions - mashups by integration $^{24}$ - are based on the use of semantic web technologies. Specifically, they could be most effectively realized through the combined use of ontolo- 
gies and Linked Data principles as they allow for seamless integration of data and knowledge originating from different, often dispersed sources [13]. In addition, the structure and semantics that ontologies add to the captured, stored and interlinked data/ knowledge provide an excellent basis for the development of advanced learning services, as demonstrated in $[39,27,40]$. Furthermore, by facilitating the integration of data about all learning activities and learning-related artifacts from different contexts and sources of learning, ontologies and Linked Data paradigm enable the creation of very comprehensive and dynamic e-portfolios. These portfolios can be further enhanced through semantic annotation of different kinds of content being used/created/shared by an individual, as well as her/his undertaken or planned learning activities. The Linked Open Data cloud $^{25}$ offers plenty of vocabularies (ontologies and datasets) that could be leveraged for semantic annotation of all kinds of learning-related resources; services such as DBpedia Spotlight ${ }^{26}$ already enable this kind of advanced content annotation. This further enables semantic interlinking (i.e., connecting based on meaning) of diverse kinds of components of a learning process (e.g., activities, knowledge objects, people) and facilitates the provision of advanced search, discovery and recommendation services for learners.

\subsection{Principle 2: Openness}

This principle refers to: open standards, open content and open source software. Its first component, open standards, is quintessential for the realization of the above mentioned integration principle, since it is the key prerequisite for applications and data interoperability and integration. All Semantic Web technologies have been developed as open, community driven initiatives coordinated by the WWW Consortium (W3C) ${ }^{27}$. This trend is entering the Social Web as well, and there are emerging open standards, such as OpenID ${ }^{28}$ and Activity streams ${ }^{29}$. However, more rapid uptake of open standards on the Social Web is hampered by the interests of big enterprise players aiming to establish their own dominance over the Social Web space.

According to the latest, 2010, Horizon Report ${ }^{30}$ [41], our second component of openness - open content - can be characterized as one of the key trends in education in the last few years, promoted and led by the leading world universities and accepted by numerous educational institutions and practitioners worldwide. This yearly report suggests that the open content movement reflects the change in the perception of education in academia, and the recognition that learning is more about activities around the content than the content itself. Besides professionally authored open content (available through, e.g., MIT's Open Courseware Initiative ${ }^{31}$ or Open Knowledge Foundation $^{32}$ ), a significant source of educationally valuable open content are (social) Web users who share their knowledge and experience through wikis, blogs, Q\&A forums, micro-blogging platforms and other online communication channels. For the realization of advanced PLEs (i.e., mashups through integration), the open datasets that are part of the Linked Open Data (LOD) Cloud are of special importance as they offer data that can be easily combined (mashedup) and thus used to "fuel" diverse educational applications. Among many relevant LOD datasets, of particular importance are those comprising (meta)data about courses and learning resources published by universities. Current leaders in linked data publishing are UK universities: Open University, University of Southampton $^{33}$ and Oxford University ${ }^{34}$. In addition, (meta)data stored in learning content repositories have started being exposed as linked open data [42]. Educational semantic social networks, such as Metamorphosis $+^{35}$ are exposing data about shared learning resources as linked open data [43]. The principles of linked data also have a significant potential to increase integration of different educational/learning systems of interest (e.g., as shown in our case study later in the paper).

The continuously growing quantity of diverse and constantly evolving educational content opens up unprecedented possibilities for both teachers and learners, but also imposes a new challenge - how to make effective use of the available content. The previously mentioned “Open Educator as a DJ" metaphor has a potential to address this challenge and enable effective use of the available open content. Following the interactivity principles, we generalize this metaphor to include also learners. In other words, we suggest that all participants in the learning process could effectively use open content through the cycle of content sampling, (re-)mixing and presentation. Since this practice requires combined use of different kinds of software tool (integrated in a PLE) and interaction with both content and other participants in the learning process, an interactive PLE provides an excellent environment for its realization.

The third kind of openness - open source software - has made such significant contributions in so many domains, education being just one of them that we 
decided to include it in the list of principles for successful realization of interactive PLEs. If made open sourced, a software solution for e.g., data integration across diverse tools, could be reused and further developed (by either individual developers or groups/organizations), thus contributing to the improved implementation of interactive PLEs.

\subsection{Principle 3: Distributed identity management}

This principle is essentially about the users' ability to control and manage their 'identities' and online presence across different tools/services that are part of their PLEs. It includes the users' ability to seamlessly access different tools/services that are part of their PLEs; to pull together their profile data from those tools/services; and regulate the use of their data within tools/services that form their PLEs.

The first component of this principle, seamless access to web applications, is in the center of interest of open web initiatives, such as OpenID and WebFinger $^{36}$ for user identification, and OAuth ${ }^{37}$ for user authentication. An increasing number of social software and SSW tools (e.g., significant portion of those mentioned in Table 1) is using some of these protocols to provide their users with easy access points. In addition, some recent research work has been directed towards devising methods for unique identification of users on the Social Web by using the people's public profile data on diverse online applications (mostly social networks). For example, Carmagnola et al have presented the preliminary results [44] of their research work aimed at uniquely identifying users on the Social Web and retrieving the data stored in their profiles across Social Web applications. The suggested approach does not require the provision of user's authentication data and user identification is performed by using the public data available on the Web. Even though it offers promising results, this approach needs to be further worked on in order to become really usable.

The second component of this principle - seamless integration of users' profile data - is related to and can benefit from the research work done in the area of distributed user modeling (e.g., [45,46]). From the inception of this research challenge, i.e., the recognition of the need for integrating users' profile data from different online applications, ontologies have played a significant role in the proposed solutions (as shown in e.g., $[47,48])$. As one of the key representatives of the SSW trend, and one of the most widely used ontologies on the Web today, the FOAF (Friend of a Friend $)^{38}$ ontology has become the basis for building domain/application specific ontologies for user modeling. In addition, it has served as a common data format for mapping to and thus integrating user's profile data from popular Social Web applications (as shown, e.g., in [49]). While FOAF is about static user profiles dealing mostly with user's persistent characteristics, the notion of Online Presence is about dynamic and changeable characteristics (e.g., status messages, availability for chat, etc) that are related to user's current appearance in the online world. The Online Presence Ontology (OPO) enables the integration, exchange and common interpretation of Online Presence related data [50]. Thanks to the shared understanding of the online presence, tools/services of a PLE can adapt their interaction with the learner by considering social factors such as who is online, who to contact, who is nearby, and how to contact. This further leads to the provision of advanced peer, expert, and teacher finding services, and thus benefits student-student and student-teacher interactivity [51].

Finally, the third component of the Distributed Identity Management principle - the user's ability to seamlessly regulate the use of their data in different online applications - can be realized through the definition/configuration of various types of policies, primarily those related to privacy and access control. Ontologies have proved as beneficial technology in this domain as well. For example, Kruk et al [52] have used the FOAFRealm ontology for letting users define fine grained access rights for their resources. FOAFRealm ontology [53] is an extension to the FOAF ontology which allows users to express how well one person knows, or trusts, another. Access control is based on the distance and the friendship level between users which is expressed using FOAFRealm. However, in this domain, ontologies are even more advantageous if they are used in combination with policy languages such as Ponder, KAoS, Rei, PeerTrust, and XACML [54]. Typically defined over ontologies, policy languages provide a reliable mechanism for (rule-based) reasoning in open environments, such as PLEs, where the use of roles and institutions the users may belong to is not applicable [55]. Current policy languages allow for contextbased reasoning where one can only leverage the knowledge coming from the shared vocabulary (i.e., ontology) of a community and the individual's reputation in the community. However, management of policies today requires a lot of technical knowledge, which prevents wider adoption of policy-based approaches in educational settings. Accordingly, there 
is a need for the development of user-friendly interfaces for policy management. Moreover, one cannot expect that end-users will define a policy for all the different ways they want to regulate the use of their data. Accordingly, there is a need to develop mechanism for automatic, context-aware detection of situations that potentially violate users' requirements/preferences regarding the usage of their data, by leveraging the ontology-based definitions of contexts. To make the policy-based approach even more applicable in educational settings, there is a need to investigate policy languages that allow for reasoning over socially constructed knowledge, in addition to the formally defined ontologies.

It should be noted that this principle is tightly related to the User Centricity principle and e-portfolio approach; actually it is a prerequisite for these two. It is also closely related to, and dependent on the Integration principle. Finally, the user's ability to seamlessly regulate data ownership and privacy is not only the key component of this principle, but is also strongly related to the principles of Openness and Ubiquitous Data Access.

\subsection{Principle 4: Context-awareness}

The abundance of resources (content and services) available over the Internet, makes it difficult for learners to find specifically those resources that would be relevant for their learning task/objective; hence the need for an assistance by the learning environment. Context-aware software environments offer a solution as they attempt to improve the efficiency of the user's interaction with the environment through capturing and making use of data about relevant aspects of the user's current situation (i.e., context). The improvement in the interactivity typically originates from improved quality of search results, proactive recommendations, and mediation of communication, among other things [56].

Despite the diversity in interpretations of the notion of learning context, researchers seem to agree that it is about the environment, tools, resources, people (in terms of social networking), and learning activities [57]. Being more specific, context in learning is mostly characterized by the learners, learning resources (content and tools) and a set of learning activities that are performed in the light of a specific pedagogical approach. Due to their flexibility, expressiveness and extensibility, ontologies have been accepted by many researchers as the most suitable mean for context modeling (e.g., [58,59,39]). Ontol- ogies ensure that different entities that use the context data have a common semantic understanding of that data. They also come with reasoning mechanisms over the available context data, making it possible to extract inferred knowledge out of the implicitly stated situations. Through the context awareness, learning environments can also provide adequate pedagogical support (e.g., guidance or instruction).

In our previous work, we have developed LOCO (Learning Object Context Ontologies) as a comprehensive ontological framework aimed at formally representing diverse kinds of learning contexts (i.e., learning situations), as well as diverse kinds of interactions that occur during a learning process (i.e., students' mutual interactions and their interactions with the learning content) [39]. LOCO allows one to formally represent all particularities of a given learning context: the learning activity, the learning content that was used or produced, and the student(s) involved. Accordingly, the framework integrates a number of learning-related ontologies, such as learning context ontology, a user model ontology, and domain ontologies. The ontologies are designed to harness the value of Linked Data paradigm by reusing and being based on ontologies such as Friend of a Friend (FOAF) and Socially-interlinked Online Communities (SIOC). Moreover, they are also designed to be compatible with the relevant e-learning standards such as IMS Learning Design. These ontologies allow for preserving the semantics of any given learning context in a machine interpretable format and thus provide the foundation for the development of context-aware learning services (as we show in the subsequent sections). We have integrated LOCO with the aforementioned Online Presence ontology in order to enrich the LOCO-based definition of learning context with the online presence data [51]. This was motivated by the fact that the inclusion of social software tools/services in online learning environments, PLEs not being an exception, has made users' online presence an integral part of any learning situation (i.e., context). Finally, in the scope of the IntelLEO EU (FP7) project, we have evolved this framework to secure support for context-aware learning and knowledge building in workplace learning settings [60].

In the following sections we present how contextawareness, achieved through the use of semantic web technologies, lead to the development and deployment of advanced learning services within the DEPTHS PLE ${ }^{39}$ and positively influenced different interactivity dimensions (student-student, studentteacher, student/teacher-content) of this PLE. 


\subsection{Principle 5: Modularity}

This principle refers to the ability to seamlessly “configure” a PLE for any given purpose (i.e., learning goal), by adding new and/or replacing existing content, tools and/or services. Currently, this principle is realized in aggregation-based educational mashups (e.g., personal dashboards) which allow learners to put together content from different sources (mainly feeds and widgets) into a single interface. Some online learning systems, Haiku ${ }^{40}$ being a notable example, allow learners to incorporate well-known social software tools/services by choosing them from a wide selection of available tools/services (e.g., Haiku offers over 80 social software tools ready to be embedded with just a simple drag-and-drop). The drawbacks of such mashups include the user's low level of control over what and how is present (e.g., there is no support for setting custom filters for the data supplied by a service), and their static nature (the data sources are predefined and cannot be dynamically changed).

From the modularity perspective, an advanced PLE could be realized through dynamic service composition based on standardized description of services deployed within a service-oriented architecture [61]. Furthermore, if services' descriptions are enriched with formal semantics (i.e., annotated with concepts coming from ontologies), service composition could be partially automated thus facilitating the creation and maintenance of a PLE and improving user's experience. An initial work in this direction is presented in [25].

An alternative solution for data modularity, that is, for the realization of dynamic data mashups is to use SPARQL [62] queries on top of linked data to integrate data originating from potentially different sources, and filter the resulting data stream based on personal preferences. Even though advantageous in terms of the offered functionality (over the current static and non-adaptive mashups), this approach is presently not applicable in educational settings since it is still overly complex for non-technical users. However, semantic web interfaces have been significantly evolving (as shown, e.g., in the series of workshops on Semantic Web User Interaction ${ }^{41}$ and summarized in a recent presentation by D. Degler [63]) and we can expect that it is not far away when these advanced solutions become usable in educational settings.

\subsection{Principle 6: Ubiquitous data access}

This principle emerges from the proliferation of mobile devices which made numerous aspects of our lives, education included, ever more mobile. Accordingly, individuals increasingly need the ability to have access to their data from whatever device they are using in the given moment. In addition, webbased applications are having even higher growth rate, resulting in a huge number of available online applications, among which a significant number can be used for educational purposes (see section (Semantic) Social Software Tools in e-Learning: State of the Practice). The challenge with respect to this trend is to provide users (learners and educators) with access to all relevant resources regardless of the application they are using at the given moment. Specifically, this implies the need for letting users access and integrate their profile data scattered across diverse applications they use. Additionally, it assumes the learners' ability to access data about their learning activities and achievements (e-portfolio). These requirements are tightly related to the previously discussed Integration and Distributed identity management principles, and as indicated in the discussion about these principles, the technology is available, and even though it is maybe not mature enough, the real challenge is not technical. Instead, the challenge is in making a shift in the ownership of data and content - switching it from companies, to users [64].

In addition, this principle is related to the users' ability to ubiquitously access and manage artifacts they have (co-)authored as well as their work in progress. This is currently supported by online Office-like environments (also known as "office in the cloud”), such as Google Docs or Zoho ${ }^{42}$. These authoring environments, equipped with constantly increasing number of collaboration features and accessible through web browser, offer users any-time and any-place access to their documents, and all the advantages of modern collaborative authoring tools. In addition, these application are beginning to adopt the principles of openness by letting their users take their data/content across the application "walls" (e.g., it is possible to directly import any existing documents from Google Docs to Zoho Docs in order to use some features of Zoho Docs not available from Google Docs). 


\subsection{Principle 7: User centricity}

The notion of PLE recognizes the role of an individual in organizing his or her own learning [9]. It assumes an active learner who is in control over his/her learning process, by taking initiative in learning and responsibility for managing his/her knowledge and competences. This makes PLE closely related to the concept of Self Regulated Learning (SRL) [65] and the portfolio approach [66]. Through the different tools and services they integrate, PLEs allow learners to plan and document their personal learning processes, to store personal reflections, self- produced artifacts and other evidences of acquired competences. This could be effectively enabled by using the Linked Data principles that allow for seamless integration of data about learning activities in various systems and connecting them through the different learning contexts. In addition, a PLE can further support a self-directed learner by offering the content and learning tasks appropriate for the learner's present learning context. It is obvious that this non-technical principle is closely related to and depends upon all the above described technical principles (1-6).

Principles for the development of Interactive PLEs

\begin{tabular}{|c|c|}
\hline $\begin{array}{l}\text { Principle 1: } \\
\text { Integration }\end{array}$ & $\begin{array}{l}\text { Integration of distributed and heterogeneous data sources, tools and services } \\
\text { Quintessential for the realization of all other principles, and thus development of advanced PLEs, i.e., PLEs } \\
\text { offering context-aware and personalized learning, as well as ubiquitous data access }\end{array}$ \\
\hline Principle 2: Openness & $\begin{array}{l}\text { Open standards => application and device independence, long-term access to content and services, interopera- } \\
\text { bility } \\
\text { Open source software => cost-effective customizations to the users' needs, } \\
\text { Open content => more diverse and constantly evolving and improving educational content }\end{array}$ \\
\hline $\begin{array}{l}\text { Principle 3: } \\
\text { Distributed Identity } \\
\text { Management }\end{array}$ & $\begin{array}{l}\text { The users' ability to: } \\
\text { - } \quad \text { seamlessly access different tools/services that are part of their PLEs; } \\
\text { - } \quad \text { pull together their profile data from those tools/services; } \\
\text { - } \quad \text { regulate the use of their data within tools/services that from their PLEs. }\end{array}$ \\
\hline $\begin{array}{l}\text { Principle 4: } \\
\text { Context-awareness }\end{array}$ & $\begin{array}{l}\text { Improved efficiency of user's interactions with the environment through capturing and leveraging data about } \\
\text { the user's learning context; } \\
\text { Improvements: higher quality of search results, proactive recommendations, mediation of communica- } \\
\text { tion/collaboration }\end{array}$ \\
\hline Principle 5: Modularity & $\begin{array}{l}\text { The ability to seamlessly “configure” a PLE for any given purpose (i.e., learning goal), by adding new and/or } \\
\text { replacing existing content, tools and/or services } \\
\text { Support for standardized and light-weight approaches for the development of dynamic (e-learning) mashups. }\end{array}$ \\
\hline $\begin{array}{l}\text { Principle 6: Ubiquitous } \\
\text { data access }\end{array}$ & $\begin{array}{l}\text { Seamless access to and integration of profile data, data about learning activities and learning resources } \\
\text { Ability to access and use relevant resources regardless of the system/tool/service the user is currently using }\end{array}$ \\
\hline $\begin{array}{l}\text { Principle 7: } \\
\text { User Centricity }\end{array}$ & $\begin{array}{l}\text { The 'user at the centre' paradigm - student is responsible for managing his/her individual knowledge and com- } \\
\text { petences } \\
\text { The learning system is the facilitator: it identifies the appropriate resources, adapts them to the user's learning } \\
\text { context, and suggests the most appropriate learning strategies }\end{array}$ \\
\hline
\end{tabular}

We have further explored the principles shown in Table 1 during the development of DEPTHS (DEsign Patterns Teaching Help System) - an interactive collaborative learning environment in the domain of software design patterns [67].

\section{Case study: Development of the DEPTHS Personal Learning Environment}

DEPTHS is our proof-of-the-concept PLE that follows the identified principles (Sect. 3). Its architecture and implementation are based on the SSW and Linked Data paradigm and the use of ontologies as a common base for the integration of different learning systems and tools in a common environment. It enabled us to get a hands-on experience with the application of the proposed principles and to test their feasibility with the current technology (i.e., to what extent these principles can be applied with the stateof-the-art technology). The identified challenges and lessons learned are discussed in Section 5.2.

\subsection{Pedagogical Approach}

Having in mind that effective learning of software DPs requires a constructivist approach to be applied in the teaching process, we have identified two important theories in this field: Project-based learning (PBL) and Engagement theory. PBL is a teaching and learning model that organizes learning around projects. Projects comprise complex tasks and activi- 
ties that involve students in a constructive investigation that results in knowledge building. PBL is sometimes mistakenly interpreted as Problem-based learning. However, despite many similarities, project- and problem-based learning approaches are not identical. The main difference between them is in the extent to which the end product (project in project-based learning, and problem solution in problem-based learning) is organized: in the project-based learning, end products are elaborated and may require extensive planning and labor, while in the problem-based learning, end products are simpler and more summative. The engagement theory is based upon the idea of creating successful collaborative teams that work on tasks that are meaningful to someone outside the classroom [68]. Based on the guidelines for teaching Software Engineering to students (e.g., [69]), and our own teaching experience, we believe that the presented theories provide a solid base for effective learning of software DPs. Accordingly, we based the DEPTHS framework on them.

A typical scenario for learning software patterns with DEPTHS assumes a project-based learning approach with collaborative learning support. In particular, a teacher defines a specific software design problem that has to be solved in a workshop-like manner, i.e. student has to propose software project as the solution of the given problem. A workshop is a peer-assessment activity with a huge array of options, such as allowing students to review and assess each other's solutions. Students' engagement in solving the problem and the support provided by DEPTHS are presented in Figure 1. Specifically, based on a student's current learning context, DEPTHS suggests other students, experts and/or teachers who can be contacted for additional support (via the Experts, teachers and peers discovery service) (A). Using the Web resource finding service and the Service for discovery of relevant internally produced resources, DEPTHS will also suggest the learning content which might be useful for the student's task at hand (B). The system currently does this on the student's request but we plan to also include proactive recommendations. Finally, it lets students to collaboratively annotate and comment on the learning resources during the problem solving process (C). As DEPTHS provides seamless integration of all of its tools, students are able to communicate and collaborate regardless of what specific tools of the DEPTHS environment they are using at that moment. 


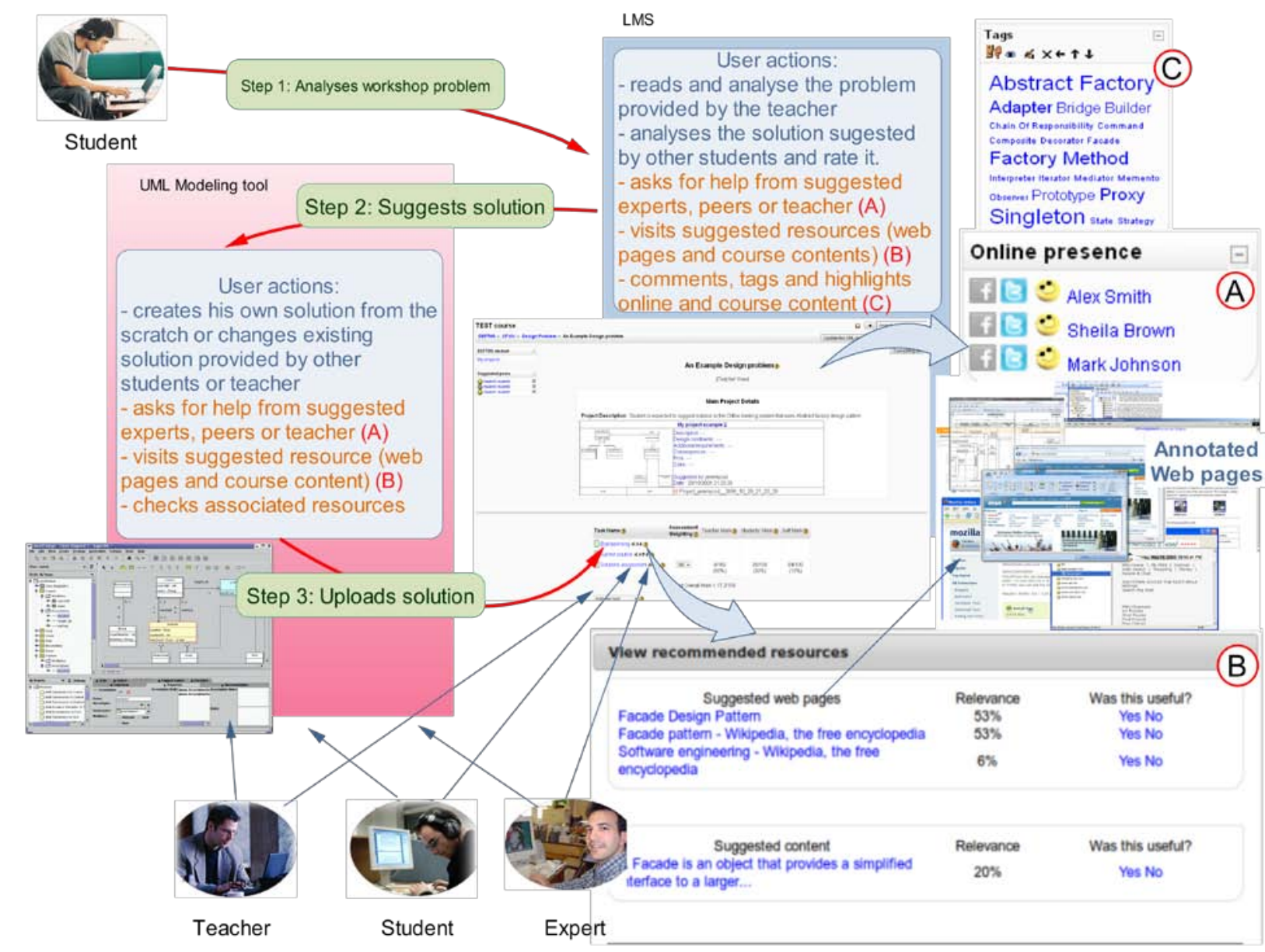

Fig. 1. A typical learning scenario for the DEPTHS environment

It is possible to develop many other learning scenarios where DEPTHS would prove as beneficial for the learning process. For example, let us suppose that a student, who uses DEPTHS, is experiencing problems with his assignment related to the Composite design pattern. He would like to ask some of his classmates for help, but he does not know who have already done that assignment and how to reach them in that moment, so he decided to rely on the system's recommendation. Having analyzed his current learning context, the system recognizes that some of his classmates have already mastered Composite design pattern and would be able to help. However, the two of them whom the system recommends as the most appropriate 'helpers' are currently not using the same learning tool (e.g. LMS) as the student requesting help. Luckily, they are using another tool integrated in DEPTHS (e.g., modeling tool) and thus, can be contacted. The contact could be initiated through chat (yet another tool that is a part of the DEPTHS envi- ronment) and further developed through any of the tools integrated into DEPTHS.

\subsection{Architecture}

Figure 2 illustrates the architecture of DEPTHS. It integrates existing, proven learning systems, such as a Learning Management System (A), a Software Modeling Tool (B), a Feedback Provisioning Tool for teachers (C), a Collaborative Annotation Tool (D) and Online Repositories of software patterns (E). This integration is achieved through the use of ontologies that comprise the LOCO framework (F). Specifically, the LOCO ontologies serve as the basis for storage and exchange of data among DEPTHS components.

LOCO (Learning Object Context Ontologies) (Jovanovic et al, 2007b) is a generic ontological framework capable of formally representing particularities of the given learning context. We define learning 
context as a specific learning situation, determined by: the learning activity that was performed (e.g., reading, posting, or discussing), the learning content that was used or produced (e.g., lesson, Web page, or forum posting), and the user(s) involved (student(s) and/or teacher(s)). When defining the notion of learning context we wanted to have a common model for representing interaction data, that is, the data that different learning systems/tools keep track of and store. Accordingly, the notion of learning context as defined here can be considered as the basic description of a specific learning situation which can be extended to support the requirements and features of any specific learning environment. The ontologies integrated within this framework (e.g., user model ontology, content structure ontology, and domain ontology) allow one to formally represent all the details of any given learning context, thus preserving its semantics in a machine interpretable format and allowing for the development of context-aware learning services. The ontologies of the LOCO framework were developed by following the Linked Data Principles and Best Practices [70]. Accordingly, linkages were established (primarily through subclass relationship) with well-known Web ontologies such as the Dublin Core vocabulary ${ }^{43}$, FOAF (Friend-Of-AFriend $^{44}$, and SIOC (Semantically Interlinked Online Communities ${ }^{45}$ ). These ontologies provide a suitable infrastructure for implementing most of these prin- ciples of SSW-based learning (as explained in the Compliance to the Principles section).

DEPTHS currently makes use of two ontologies of the LOCO framework: the Learning Context ontology and domain ontology. The Learning Context ontology allows for semantic representation of the data about student's overall interactions with learning content and other students during different learning activities. This ontology was extended to allow for the representation of learning contexts specific to the systems, tools and services often used in software engineering education and thus integrated into DEPTHS. In particular, the kinds of learning activities recognized by the Learning Context ontology (e.g., reading a lesson, posting a chat or forum message and doing an assignment) were not enough to meet the specific needs of the DEPTHS environment. Therefore, we extended this ontology with a set of classes and properties for modeling project-based collaborative learning. Moreover, the Learning Context ontology has been extended with additional types of learning content (i.e., subclasses of the ContentUnit class), namely DesignProblem, Task and Diagram (Figure 3). Based on the data captured by the (extended) Learning Context ontology, DEPTHS can perform context-aware retrieval of resources on software design patterns (DPs) from online repositories and its own repository of software design artifacts (which contains artifacts produced by students and those shared by the community, Figure 2).

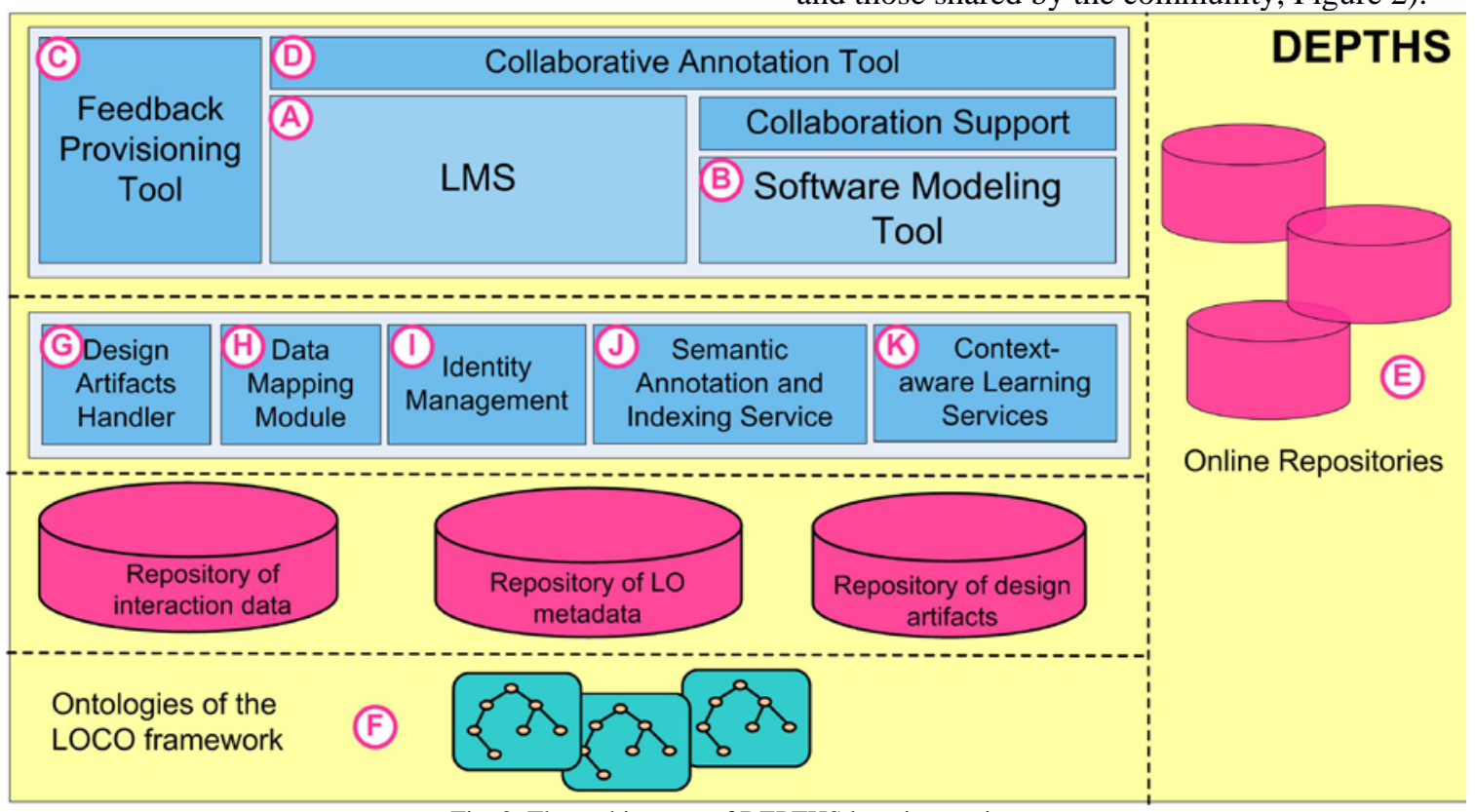

Fig. 2. The architecture of DEPTHS learning environment 
Since DEPTHS is devised as an environment for teaching/learning software DPs, we needed a domain ontology that formally represents the domain of software DPs. Rather than developing a new ontology from scratch, we (re)used an existing ontology. Specifically, we have chosen the set of ontologies suggested in [71] as it provides a very intuitive and concise way to describe DPs and pattern collections, and to offer more information on usability of DPs in software architectures. These ontologies are used by the Semantic annotation service to semantically annotate learning content (see section Implemented Architecture).

The above presented LOCO ontologies are used as the basis for storage and exchange of data among DEPTHS components. In particular, these ontologies underlie two DEPTHS repositories:

Repository of Interaction Data stores data about students' interaction with learning content, as well as their mutual interactions in the learning environment. It actually stores learning context data in the form of RDF triples compliant with the (extended) Learning Context ontology.

Repository of LO Metadata stores semantic metadata about all kinds of learning objects (LOs) used in the courses under study: lessons and resources available from online repositories, as well as user generated content, such as software design diagrams, discussion forum and chat messages. We refer to these metadata as semantic metadata, as they formally describe the semantics of the learning content they are attached to. This is done by relating LOs with the appropriate concepts in the ontology of software Design Patterns (DP), in the following manner: \{loco:LearningObject $\}$ loco:hasDomainTopic \{depths:DesignPattern .

The data in these two repositories are interlinked. The linking of data across these two repositories enables us to seamlessly relate students' interactions with the content used and/or produced during those interactions and to identify interactions related to the same domain topics (i.e., DPs). By leveraging these and similar possibilities enabled through the use of linked data, we were able to develop recommendation services described below. Currently, we do not publish these data on the Web as linked data. However, we intend to expose as linked open data, the metadata that we generate for the learning resources from the public repositories of software DPs since we believe that these (meta)data could be useful to others who are e.g., developing similar educational applications with adaptation and/or recommendation features.

DEPTHS also includes a Repository of Design Artifacts that stores software artifacts created by students, such as UML class diagrams. These artifacts are maintained in two open standard formats: XMI (XML metadata interchange) format that is appropriate for later reuse, and SVG (Scalable Vector Graphics) that is suitable for presenting the artifacts in the Learning Management System. In addition, they are suitable for semantic annotation with domain ontologies. This repository is maintained by the Design Artifacts Handler ( $\mathrm{G}$ in Figure 2).

Since different learning systems, tools and services use different formats for representing and storing interaction data, DEPTHS integrates a Data Mapping Module ( $\mathrm{H}$ in Figure 2) that performs the mapping of the data generated as the result of learners' activities and stored in the native data format, into RDF triples compliant with the LOCO's learning context ontology (i.e., interaction data are transformed into LOCO context data). In addition, this module is responsible for intercepting different types of events that occur during the users interaction with the tools integrated into the environment, and storing the (meta-)data about those events as RDF triples compliant with LOCO's ontologies. The RDF data generated by this module are stored in the Repository of Interaction Data. Data mapping is performed throughout each learning session in order to keep the semantic repository updated (with data about the interactions occurring during that session). More details about this module as well as other components of the DEPTHS architecture can be found in [72]. 


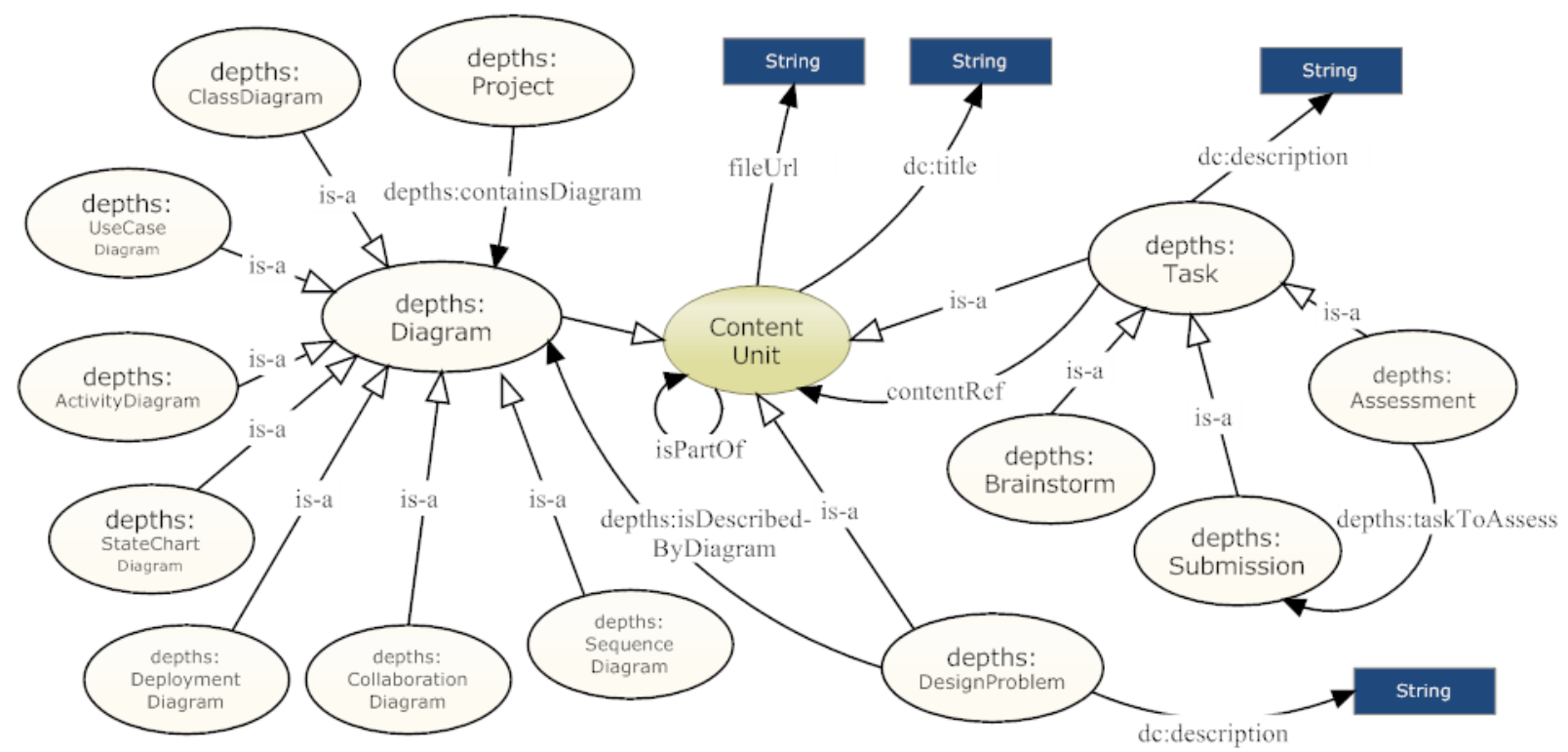

Fig.3. The extension of Learning Context ontology: the ContentUnit class and its DEPTHS-specific subclasses

Identity Management Component (I in Figure 2) enables learners to seamlessly access all learning systems/tools integrated in the DEPTHS environment in spite of the fact that they all may require different access accounts. More importantly, this allows for ubiquitous access to the data available within the DEPTHS environment regardless of the system the data was originally created and stored in. In our present implementation, we opted for the use of OpenID due to its simplicity. Each time a learner accesses a tool within the DEPTHS environment, s/he is presented with the OpenID login form. Once the learner is verified by the OpenID server, s/he is automatically logged in any other tool integrated within DEPTHS. This eliminates the need for multiple usernames across different tools.

Semantic Annotation and Indexing Service ( $\mathrm{J}$ in Figure 2) is used for semantic annotation and indexing of documents from publicly-accessible repositories of DPs, as well as the learning content created by students and teachers (e.g., exchanged chat messages, discussion forum threads, or assignments). This module uses semantic annotation services of the KIM (Knowledge and Information Management) ${ }^{46}$ platform to automatically annotate documents in the publicly accessible online repositories of software DP as well as students' projects stored in the Repository of Design Artifacts. As a result of this annotation process, documents and students' projects are associated with topics (concepts) from the ontology of software patterns. Semantic Annotation and Indexing Service uses the term frequency-inverse document frequency (TF-IDF) [74] to measure what each document is about (based on the domain topic most frequently found in the document) and how relevant the document is for the whole document collection. Thus, the more frequently a domain topic appears in a document, it is considered as more significant in the document. However, if a domain topic is very frequent in the whole document collection, it is not considered to be particularly representative for any document. Additionally, for each indexed document, we also capture the relevance value which indicates how relevant that document is for a specific domain topic. This relevance value is computed as a cosine similarity between the TF-IDF value of a document and the domain topics it contains (more details on this can be found in [27] and [72]).

Context-aware Learning Services (K in Figure 2) are accessible to all systems and tools integrated in the DEPTHS environment and are exposed to end users (students) as context-aware learning features.

\subsection{Context-aware Learning Services}

These services use the data from DEPTHS repositories to provide students with additional, contextaware learning support. They include (but are not limited to) the following:

Web resource finding. Based on the student's current learning context, this service finds potentially useful Web resources (Figure 4). DEPTHS uses relevant, publicly accessible repositories of software DPs 
as the source of potentially relevant Web resources. In particular, it currently makes use of Yahoo! Design Pattern Library ${ }^{47}$, Portland Pattern Repository ${ }^{48}$, and Hillside.net Pattern Catalog ${ }^{49}$. The service uses the semantic annotations of the resources available from these repositories (generated by the DEPTHS's Semantic Annotation and Indexing Service) to identify those resources that are relevant for the given learning context. The relevance of a resource is cal- culated according to its relatedness to the domain ontology concepts (i.e. software patterns) relevant for the current learning context, and the students' previous ratings of the resource [27]. All resources found to be relevant are sorted based on their relevance for the current context. More details about this service as well as other context-aware services, briefly outlined below, can be found in [72].

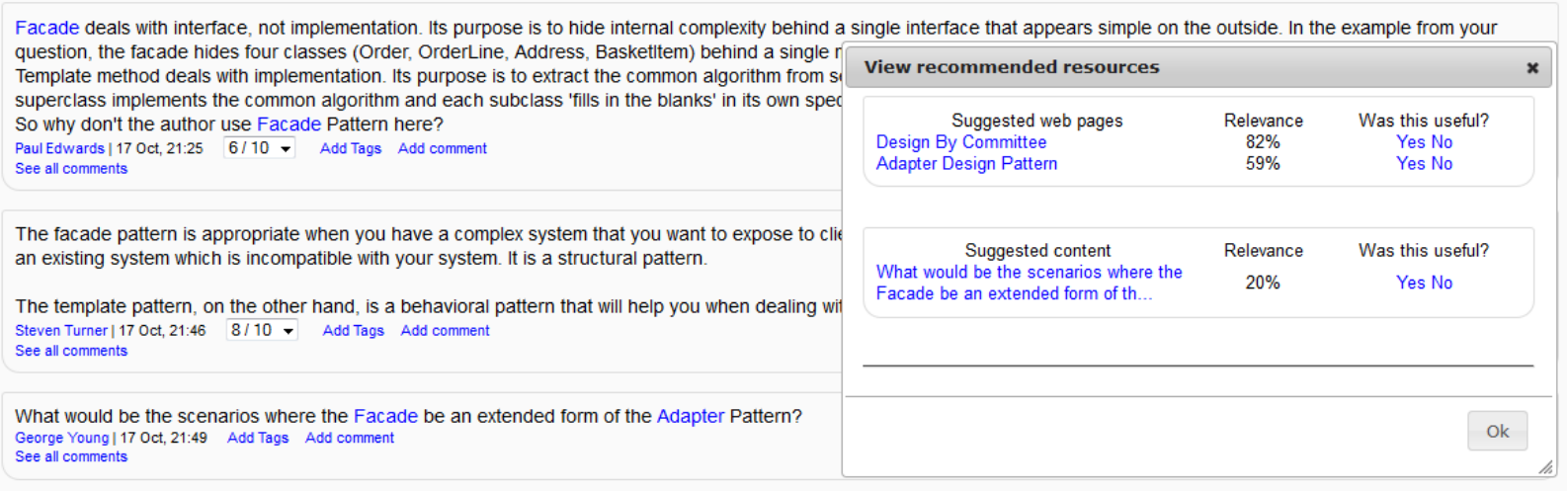

Fig.4. A screenshot presenting the use of the Web resource finding service and the service for the Discovery of internally produced content, with the brainstorming task.

Discovery of relevant internally produced resources. This service suggests internally created resources (e.g., discussion threads, brainstorming notes, and project descriptions) that could be useful to a student when solving a problem at hand in the given learning context. The computation of relevancy for the internally produced resources is done in a way similar to the one used for external Web resources [27].

Discovery of experts, teachers and peers. Based on the current learning context, this service suggests other students or experts as possible collaborators (Figure 5). Collaborators are selected and sorted using an algorithm which considers their competences on three different levels: same content (i.e., the current software problem), similar or related learning content (i.e., a similar software problem) and broader content (i.e., a software problem in the same course). Estimation of a peer's competence on each level is performed through assessing three types of competence indicators [27]:

- participation in learning activities (e.g., brainstorming, submitting a solution to the software problem or assessing peers' solutions). Each ac- tivity has a different impact factor on the system's estimation of the student's competences. This factor is defined in the system but could be changed by the teacher.

- knowledge level estimated by the teacher and obtained through the peers' evaluations, including projects evaluations and idea ratings. However, not all ratings have the same influence on the knowledge level estimation. For example, a high mark given by a student with high competences on the given topic has more impact on the final knowledge level appraisal than a high mark given by a student with average or low competences.

- social connections with the peer asking for help - the stronger the social connection with a specific person, the more suitable that person is for providing help. It has been shown (e.g., in [73]) that an already appointed social connection could be much more successful and effective than new connections with people one does not know. 


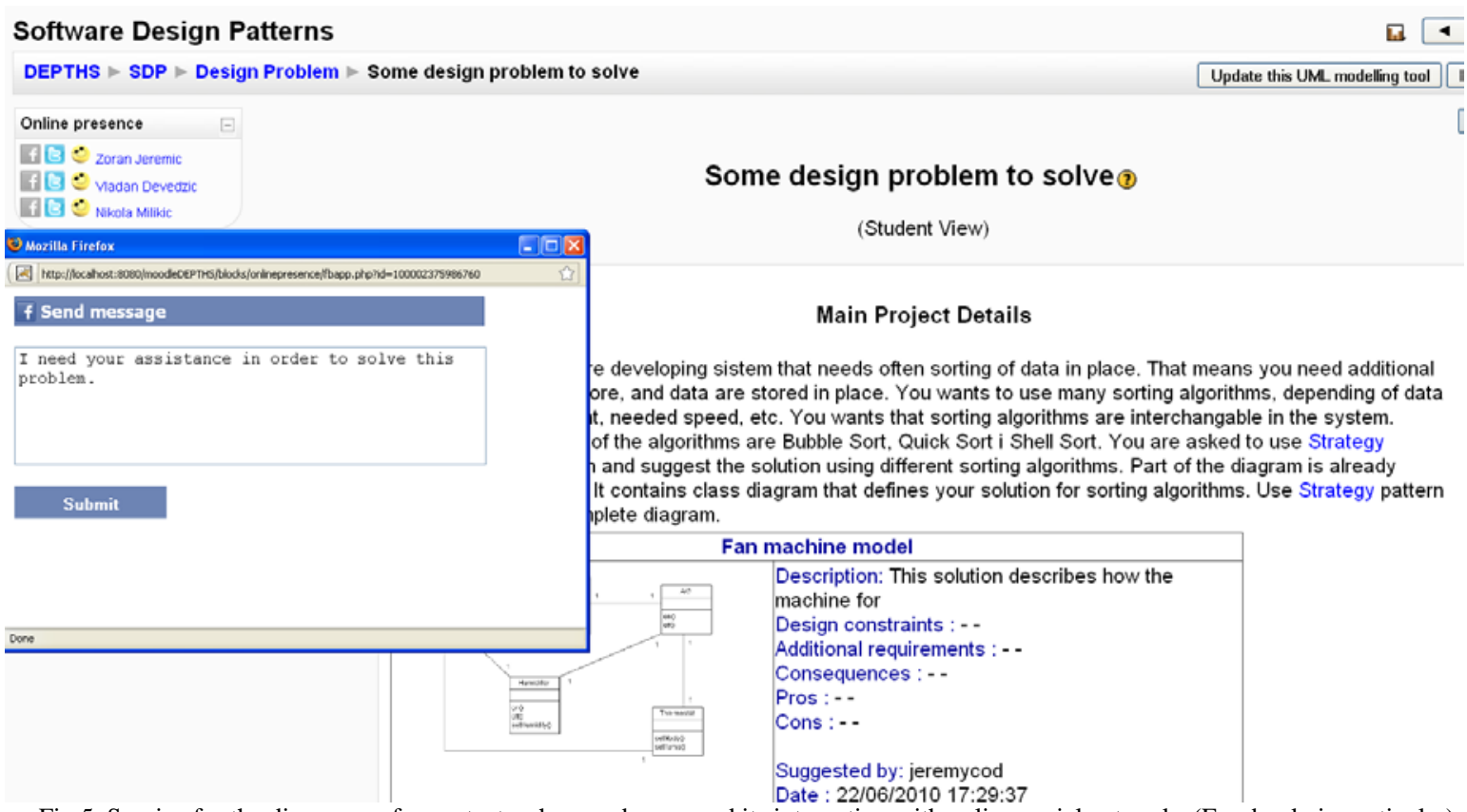

Fig.5. Service for the discovery of experts, teachers and peers and its integration with online social networks (Facebook, in particular)

Additionally, the service for the discovery of experts, teachers and peers makes use of the DEPTHS's integration with online social networks, which currently includes Facebook and Twitter. Thus, if a peer to be recommended by this service is not available in the LMS in the given moment, the service will check his/her availability on online social networks, namely Facebook and Twitter, and if s/he is available on any of these network, the student in need for help will be informed about that. The student, still working within his/her LMS, will be able to send a help request message (Figure 5) to the peer's account on one of the social networks s/he is currently active; the service will insert in the message a direct link to the learning context where the help is needed. Having received the notification, the peer can read the message and access the software design problem to check if $\mathrm{s} / \mathrm{he}$ can offer help.

Context-based semantic relatedness. This service is used by all other services, as it allows for: i) computing context-based semantic relatedness between tags that students define and/or use in the given learning contexts with appropriate concepts of the domain ontology (i.e. disambiguation of the tags with the domain concepts [75]); and ii) resolution of students' queries containing both tags and domain concepts relevant for the given learning context.

\subsection{Implemented Architecture}

The DEPTHS learning environment is implemented through the extension and integration of open-source learning system and tools. The open access to the source code of those system and tools enabled us to extend them with Semantic Web technologies and to integrate them according to the requirement of the DEPTHS architecture.

We use Moodle ${ }^{50}$, a popular open-source Learning Management System, with a variety of learning tools and features. However, to effectively support collaborative learning in the domain of software DPs, we have extended it with additional modules. In particular, we have developed a module (Figure 4) that supports activities typical for collaborative project-based learning, such as brainstorming, software artifact exchange, evaluation of peers' projects based on teacher-defined criteria, and rating and commenting ideas. To better support collaborative tagging in DEPTHS, we have extended the tagging feature offered by Moodle and integrated it in project module, as well as within discussion forums. Of course, given the openness and flexibility of DEPTHS' architecture, other general-purpose collaborative tagging, highlighting, and note-taking systems can be used. In our experiments, we have used OATS (Open Annotation and Tagging System) [76]. We have also extended Moodle with support for capturing interaction data in the form of RDF triples compliant with the 
Learning Context ontology of the LOCO framework. All these data are stored in the Repository of interaction data and could be accessed from all tools integrated in DEPTHS. Finally, our context-aware learning services are available from within Moodle.

For semantic annotation of learning content we deploy semantic annotation services of the above mentioned KIM platform. These services allow us to annotate learning content (e.g., lessons, resources from online repositories of software patterns and artifacts produced by students) with the concepts from our domain ontology (i.e., the ontology of software patterns). The resulting metadata is represented and stored in the standard format for educational metadata storage (i.e., as IEEE LOM profile encoded in RDF).

As a software modeling tool, we have integrated ArgoUML ${ }^{51}$, an open-source tool that supports the design, development and documentation of objectoriented software applications. ArgoUML has also been extended with support for working with the LOCO ontologies, so that it can exchange learning context data with all other integrated systems/tools. We have also provided support for describing software solutions and collaborative work (e.g., chat and messaging) that was lacking in this tool. Most importantly we enabled it to make use of the DEPTHS context-aware learning services.

Finally, we integrated LOCO-Analyst, a tool that uses learning context data (based on the ontologies of the LOCO framework) to provide teachers with learning analytics about all kinds of activities their students performed during the learning process (e.g., feedback about students' online interactions, or feedback about students' comprehension of domain topics based on their collaborative tags) [23].

\section{Analysis}

Having developed DEPTHS as a novel SSW learning environment, we analyzed how compliant it is to the principles that we have identified (Table 2) and how such architecture improves interactivity in the learning process.

\subsection{Compliance to the Principles}

The integrative approach (Principle 1) applied in DEPTHS is completely opposite to the currently prevalent, 'fragmented' approach that assumes individual use of systems and tools for teaching/learning software DPs. The major advantage of this approach is the seamless exchange of interaction data (i.e., data about the students' interaction with learning content and other members of the online learning community) among different systems, tools and services that students typically use when learning about software DPs. The integration of students' interaction data (Principle 1) allows for the deployment of contextaware learning services (Principle 4) that offer a personalized learning experience to students (Principle $7)$. In addition, it allows for ubiquitous access to relevant data and resources (Principle 6). Through the use of OpenID, we support identity management between systems and services integrated in DEPTHS (Principle 3).

DEPTHS integrates open-source learning systems and tools and assumes the (re)use of open learning content, that is learning content available in publicly open content repositories (Principle 1). It also uses open software standards for storage and exchange of software artifacts that students produce during the learning process.

DEPTHS modularity (Principle 4) stems from its reliance on the ontologies of the LOCO framework for data capturing and integration, as well as on the encapsulation of context-aware learning services relying on loose coupling and interoperability. In particular, DEPTHS context-aware learning services are fully based on the LOCO-based data, so the functionalities they provide are not coupled to any particular learning system or tool (i.e., to their native format for interaction data). This further means that these functionalities would be available to any new system and/or tool added to DEPTHS. The only thing that needs to be done is the mapping between the interaction data format of the new system/tool and the LOCO's learning context ontology (i.e., an extension of the DEPTHS's Data Mapping Module). Similarly, resources from new online repositories can be included (i.e., considered for recommendation), after they are semantically annotated (by the Semantic Annotation and Indexing Service) with the concepts of the domain ontology. 
Table 2

Compliance of the DEPTHS's architecture with the proposed Principles

\begin{tabular}{|c|l|l|}
\hline Principle & \multicolumn{1}{|c|}{ Short Description } & \multicolumn{1}{|c|}{ DEPTHS Component(s) } \\
\hline 1 & $\begin{array}{l}\text { Integration of heterogeneous tools and users' } \\
\text { interaction data }\end{array}$ & LOCO ontologies and Data Mapping Module \\
\hline 2 & Openness: (re-)use of open learning content & Semantic Annotation and Indexing Service \\
\hline 3 & Distributed identity management & Identity Management \\
\hline 4 & Context-awareness & Context-aware Learning Services \\
\hline 5 & Modularity & LOCO ontologies \\
\hline 6 & $\begin{array}{l}\text { Ubiquitous access to relevant data and re- } \\
\text { sources }\end{array}$ & $\begin{array}{l}\text { COCO ontologies and Data Mapping Module } \\
\text { dexing Service }\end{array}$ \\
\hline 7 & Personalized learning experience & \\
\hline
\end{tabular}

\subsection{Challenges (Experiences) and Lessons learned}

Based on our experience, including the above case study, we can state that DEPTHS' foundation on the SSW Linked Data paradigm has introduced a new quality to the learning experience. However, providing support for all the identified principles (Section 3 ), was not an easy task. We have found several difficulties caused by the technology limitations. In this section we share our experiences and lessons learned, aiming to increase the awareness of the difficulties that might arise when developing a PLE. Please notice that the reported challenges are related exclusively to the PLE development, not its use by the end users (i.e., teachers and learners).

Integration. One of the basic aspects of learning in DEPTHS is the integration of different learning resources both from internal sources (tools integrated) and external sources (web repositories). In order to provide appropriate recommendation of content originating either from internal or external sources, DEPTHS needs to have some basic understanding of that content; accordingly, it has to annotate those pieces of content, i.e., generate metadata for the content. To collect external content, DEPTHS integrates a Web crawler, a tool for collecting links of all processable web pages inside a specific online repository. However, some websites do not allow Web crawlers to process the pages inside the site, which makes such a site unavailable for DEPTHS. An implication of this limitation is that the content from some websites with high educational potential could not be effectively used within DEPTHS and similar educational environments. Without ability to directly access the content and annotate it, neither DEPTHS, nor other learning systems will be able to provide learners with advances educational services (e.g., recommendation of con- tent relevant for the given learning context). In addition, there is a problem of semantic annotation of the crawled pages and learning content in general. Even though, DEPTHS makes use of the state-of-the-art services for semantic annotation, the results (i.e., annotations) are not always on the level of quality (due to missing, imprecise or even wrong annotations) that would be required for linking content based on its semantics. This could result in recommendations that are not always best fit for a specific learning situation. We are addressing this problem by collecting students' feedback about the used learning resources and using it in the recommendation process. However, until a substantial feedback is received, students will be served with potentially inappropriate resources. Even if we disregard this problem, there is still an important impediment associated with this kind of semantic annotation; it is the need to extend the knowledge base of the annotation services with the concepts relevant for the subject domain of the resources to be annotated. In the case of DEPTHS (Section 4.2), this has been done by extending the KIM's knowledge base with the concepts from the domain ontology used by DEPTHS (ontology of software design patters). On the bright side, the need for hand-crafting domain ontologies for different subject domains (i.e., different courses, in the considered context of education) and importing them into knowledge bases of annotation services could be bypassed and thus the whole process could be significantly facilitated by making use of DBPedia and/or subject-specific datasets of the Linked Open Data cloud.

Openness. To facilitate an effective access to the content and addition of new tools in a PLE, we considered the tool's support for representation and annotation of the used content. For example, ArgoUML is compliant to the UML XMI standard, so that the produced software models can be easily 
shared with other tools. In addition, we use SVG format to share UML models between ArgoUML and Web applications (e.g. Moodle). Furthermore, the DEPTHS environment is also open in its compliance to the broadly adopted Linked Data ontologies (e.g., SIOC and FOAF), which sets the ground for sharing the data produced and used in the DEPTHS services and tools with other external systems.

Distributed identity management. None of the LMSs we have considered to integrate in DEPTHS supports any of the open web initiatives, even though they can have identity management regulated via more heavy-weight identity management approaches (e.g., LDAP). Even more, domain specific tools (e.g., ArgoUML) most often do not support any kind of user authentication. As DEPTHS builds user profiles based on their activities in different tools, it is very important to provide a common user identification for all the tools integrated within the environment. In order to deal with this problem, we implemented mapping of the user authentication data from the integrated LMS (i.e., Moodle) to the common ontology. All other tools, integrated within DEPTHS use this information to authenticate user. However, these tools had to be extended to support this. Tools that already contain authentication module are extended to check user identity against the user profile stored in the ontology, while tools that do not contain authentication module had to be extended with the module that supports authentication.

Modularity. From the modularity perspective, none of the tools we integrated within DEPTHS could be described as highly modular application. We had to extend all these tools in order to support their integration within the DEPTHS environment. Developing additional module that maps data between integrated application (i.e., its database) and common ontology was not a challenging task. However, extending applications to intercept user activities and store them in the ontology-compliant format was not so easy in case of ArgoUML due to its quite complex design and lack of modularity; the same task in Moodle demanded much less work. Moreover, switching from the version of ArgoUML we started with, to the most recent version required significant effort due to the fact that backward compatibility is not preserved. While writing this paper, we are facing the same problem with Moodle, as our module for supporting collaborative project-based learning became incompatible with Moodle 2.x architecture.

\section{Evaluation}

\subsection{Research Questions}

A formative evaluation [77] of DEPTHS was conducted in February 2009, in the context of a course that the first author of this paper taught at the Department of Computer Science of the Military Academy in Belgrade, Serbia. The evaluation study was aimed at enabling us to answer the following three research questions:

RQ1: Whether and to what extent the students perceived learning services and functionalities offered by the DEPTHS environment as valuable?

RQ2: Whether and to what extent the course design is perceived as consistent with technologies used in DEPTHS? To answer this research question we investigated how the students perceived the use of the course design within the DEPTHS environment, as well as how they perceived the contribution of the assigned learning tasks to the outcomes of their learning process.

RQ3: Whether and to what extent the students recognize the importance of and accept to take the responsibility for their own learning? Specifically, we explored if the course design encouraged the students to take responsibility for their own learning and if they perceived that DEPTHS is enabling them to take control over their learning process.

\subsection{Method}

\subsubsection{Study Design}

Giving that this was a formative evaluation performed at an early stage of DEPTHS development, our goal was not to have results that can be generalized for a target learner population, derive new learning theories, or prove causalities among some variables. Accordingly, the sample was recruited not to draw statistically significant conclusions that can be generalized to the entire target population, but rather to evaluate the present progress and perceived value of DEPTHS. As per the purpose of formative evaluation [77], we aimed to verify the adequacy of the proposed technology through identifying how the students perceived learning with DEPTHS and the consistency of the course design and technologies used in DEPTHS. This also drive the design of our data collection instrument (i.e., questionnaire) suitable for answering our research questions. Moreover, we expected to get directions for further research 
and system's improvement based on the evaluations results.

\subsubsection{Participants}

DEPTHS was evaluated with a group of 13 undergraduate (fifth year) Computer Science students who took part in our course on software development. Giving that this was a formative evaluation and the fact that study groups in senior years of Computer Science programs are typically small, we consider that the size of this study group (13) is sufficiently representative for the target audience of our research. This is in line with the purpose of a formative evaluation, which is not designed to make generalizations to the entire population, but to assess the progress of the present research and inform the future research. The students already had some elementary knowledge in the domain of software DPs, but they were not familiar with the particular software DPs used in this experiment (Facade, Adapter, Strategy, Composite, Visitor and Decorator).

The students were divided into 4 groups (3 groups with 3 students and 1 group with 4 students), based on the instructor's subjective opinion about their knowledge in the domain of software development and their previous results in the courses related to software engineering. The size of the groups was based on our teaching experience that work in small size groups (3 or 4 students) is a necessity for effective education of software engineers.

\subsubsection{Materials}

The materials used in this evaluation study included: the DEPTHS environment (including the tools and services it integrates), the DEPTHS's logs related to the use of the tools/services it integrates, the learning course with specified software design assignments and the questionnaire. In order to complete the tasks defined in the assignments, the students had to use the software tools integrated within DEPTHS, namely, Moodle, ArgoUML and educational services (peers discovery service and resource recommendation). The course contained two assignments (i.e., design problems). The first assignment was supposed to be done by students working in small study groups (3-4 students, as explained above), whereas the second one was to be accomplished by all the students working together.

We used a questionnaire to collect the data about the students' perception of the services and functionalities provided by DEPTHS. The questionnaire was also supposed to enable us to obtain the data about the perceived consistency of the course design and the technologies and tools used in DEPTHS, as well as the students' perceptions regarding the effectiveness of learning with DEPTHS. Except for the six questions that were open-ended questions, all other questions (33) were multiple-choice questions based on a five-point Likert-like scale.

\subsubsection{Study Procedure}

Before the experiment started, a demonstration of DEPTHS's functionality along with a training session in which an assignment similar to those used later in the experiment, were performed with the students. For the experiment, each student was given two assignments (i.e., software design problems), one common for all students in each group and the other common for all students involved in the study. The students were asked to solve the given assignments within sven days by following a predefined set of tasks: brainstorming, suggesting a solution and evaluating each others' solutions. However, inside each individual task, students had a freedom to choose how they would perform the task and how they would use the provided tools and services. Actually, the work on the assignments was supposed to follow the learning workflow described in Section 4.1. As a part of the brainstorming task, the students were asked to present their ideas for solving the given software design problem using a specific design pattern, and to comment on and rate ideas suggested by other students from their group. When they were all working together on the second assignment, the students were asked to make use of the Service for the discovery of peers, as a mean for improving the collaboration. Afterward, each student was asked to use the domain modeling tool (i.e., ArgoUML) to create his/her own proposal for the design problem solution and to submit it. At the end, each student was supposed to evaluate all solutions proposed by other students.

\subsection{Study Results}

In what follows, we discuss the study results from the perspective of the research questions stated above.

RQ1: Perceived value of services and functionalities offered by DEPTHS. The DEPTHS environment received high marks from the students. The students reported that the environment was intuitive 
and very easy to use (76,92\%) and they enjoyed learning with DEPTHS (84.61\%).

The students felt that educational services provided within DEPTHS were very helpful: Web resource finding service $-92.30 \%$ of the students; Service for the discovery of relevant internally produced resources - 84.61\%; and Experts, teachers and peers discovery service - 76.92\% (Principles Openness and Context-awareness).

Having analyzed DEPTHS's logs, we found that students frequently used the educational services during the experiment. Moreover, resources suggested by DEPTHS as the most relevant in the current context, were also voted as relevant by students (94.15\% of them) in DEPTHS itself. These results indicate that DEPTHS might have a very positive impact on the student-content interactions.

Having analyzed correlation between variables we have identified 27 variables' pairs that have significant association through the use of Pearson's chisquare (we used standard level of significance $\mathrm{p}<0.05$ ). For example, we found that students' satisfaction with the educational services for recommending relevant Web pages and course content affected their later satisfaction with their learning results using this program. We believe that this association is related with the students' level of adoption of these services as important and useful part of a learning system. However, a deeper analysis of these results and a follow-up summative evaluation out of scope of this paper and will be reported in our future work.

RQ2: Perceived consistency of the course design with the technologies used in DEPTHS. The majority of students (92.30\%) perceived that learning objectives, outcomes, and/or expectations for the course were clearly stated. Most of the students (84.61\%) found that helpful examples have been used in the course. They also thought that the activities provided within the learning tasks considerably contributed to the outcomes of the learning process (brainstorming - 76.92\%, and evaluating each other's works $-100 \%)$. In addition, the majority of the students (92.30\%) perceived that they learned from other students projects shared through the DEPTHS's project module. Additionally, 84.61\% of the students found ideas of other students as very beneficial and all students (100\%) indicated that evaluation of other students' works was useful for learning process. This indicates that DEPTHS has well set the scene for productive student-student interactions.
RQ3: The perceived recognition of the importance of and acceptance to take responsibility for learning. Our analysis has shown that the majority of the students (76.92\%) were encouraged to take responsibility for their learning in DEPTHS. Most of them $(76.92 \%)$ reported that they had a great deal of choice over how they are going to learn in the given project task (Principle User centricity).In addition, a significant number of the students (84.61\%) had a clear idea where they are going and what was expected from them.

We can conclude that DEPTHS provides prerequisites for user centricity (Principle User centricity) and makes students responsible for the development of their individual knowledge and competences. Moreover, even though the students were accustomed to using the Web for information access and online tools for collaboration, they did not use them in an integrated way. However, they found that when integrated (like in the DEPTHS environment), these tools are even more useful (Principle Distributed identity management). Based on the students' answers to the questions about educational services and tools provided within DEPTHS, we can infer that the principles of context-awareness (Principle Context-awareness) and ubiquitous data access (Principle Ubiquitous data access) are promising to create more productive and effective learning experience.

\section{Conclusion}

The seven key principles for interactive PLEs have been identified and empirically explored in the architecture of the DEPTHS PLE. The principles can be considered a first step towards the materialization of the concept of interactive PLE built on Social Semantic Web paradigm and Linked Data principles. The presented architecture and implementation of the DEPTHS environment demonstrates how this synergetic mix of social and semantic technologies and Linked Data paradigm advances the learning process in a very concrete domain of software engineering education. DEPTHS goes beyond narrow goals of individual courses and serves as a basis for managing life-long learning. While the benefits of the use of the Social Semantic Web and Linked Data are obviously present, two major questions still need to be solved: privacy preservation and data ownership in education and learning. This requires further research of the perception of privacy and data own- 
ership in this new networking (learning) context and an engagement of the overall Web community, not only educators. Until these important issues are resolved, Linked Data inspired local data clouds [78] will most probably dominate in the educational domain.

With regard to future work we plan to perform a more elaborate summative evaluation study with a higher number of participants. In particular, our study will be aimed to investigate the impact of the interventions implemented in the DEPTHS environment on the level of cognitive presence [79] and metacognition [80] in project-based collaborative learning. In addition, we are preparing a detailed review of the state-of-the-art and state-of-thepractice in the area that intersects social semantic web, linked data and online learning, in order to further explore the potential and implications that these novel data-driven technologies have on the interactivity and collaboration aspects of personal learning environments.

\section{Endnotes}

1. http://www.notemesh.com/

2. http://www.slideshare.net/

3. http://cnx.org

4. http://www.buddyschool.com/)

5. http://elgg.net/

6. http://www.icamp.eu/

7. http://www.nmc.org/horizon

8. http://dataportability.org/

9. http://www.deliberations.com.au/2006/12/present-andfuture-of-personal-learning.html

10. One of the most prominent example is Prof. Michael Wesch from Kansas State University (http://mediatedcultures.net/ksudigg/)

11. http://opencontent.org/blog/archives/227

12. http://edtechpost.wikispaces.com/Open+Educator+as+DJ+\%2 8Final\%29

13. http://ocw.mit.edu/OcwWeb/web/home/home/index.htm

14. http://www.opener.ou.nl/

15. http://www.talis.com/aspire

16. http://groupme.org/GroupMe/

17. Ensemble: Semantic Technologies for the Enhancement of Case Based Learning, http://ensemble.ljmu.ac.uk/wp/

18. In order to reduce the clutter and make the text easier to read, we use the term 'tool' as generic term when referring to different kinds of tools, systems and services.

19. http://semtech-survey.ecs.soton.ac.uk/

20. http://www.mkbergman.com/new-version-sweet-tools-semweb/

21. http://www.c4lpt.co.uk/recommended/top100.htm

22. http://www.c4lpt.co.uk/

23. Available as podcasts on, for example, http://www.educause.edu/podcasts, and http://cider.athabascau.ca/CIDERSessions/
24. In Section 2.3, we described both types of mashups and emphasized the advantages of mashups by integration over mashups by aggregation.

25. http://linkeddata.org/

26. http://dbpedia.org/spotlight

27. http://www.w3.org/

28. http://openid.net/

29. http://activitystrea.ms/

30. Annual report that identifies and describes emerging technologies that are expected to have significant impact on higher education practices

31. http://ocw.mit.edu/

32. http://www.okfn.org/

33. (http://data.southampton.ac.uk)

34. http://data.open.ac.uk

35. http://metamorphosis.med.duth.gr/

36. http://code.google.com/p/webfinger/

37. http://oauth.net/

38. http://xmlns.com/foaf/0.1/

39. http://learningdesignpatterns.org

40. http://www.haikulearning.com/

41. http://swui.webscience.org/

42. http://www.zoho.com

43. http://dublincore.org/documents/dces/

44. http://xmlns.com/foaf/0.1

45. http://sioc-project.org

46. http://www.ontotext.com/kim/index.html

47. http://developer.yahoo.com/ypatterns/index.php

48. http://c2.com/ppr/

49. http://www.hillside.net/patterns/onlinepatterncatalog.htm

50. http://moodle.org

51. http://argouml.tigris.org/

52. SparqlPress plugin (http://wiki.foafproject.org/w/SparqlPress) is required for providing Semantic Web functionalities

53. FOAF export plugin is necessary to provide Semantic Web functionality

\section{References}

[1] M. Eisenstadt. Does Elearning Have To Be So Awful? (Time to Mashup or Shutup), Keynote address @ IEEE 7th International Conference on Advanced Learning Technologies, pp. 6-10, Niigata, Japan, (July 2007).

[2] S. Minocha, Role of social software tools in education: a literature review, Education + Training, Emeral Group Publishing Limited, vol.51, no.5/6, pp. 353 - 369, (2009).

[3] K. Ala-Mutka, M. Bacigalupo, S. Kluzer, C. Pascu, Y. Punie, \& C. Redecker, 2009, Learning 2.0: The Impact of Web 2.0 Innovation on Education and Training in Europe, JRC Scientific and Technical Report, EUR Number 23786 EN, (March 2009) Available at: http://ftp.jrc.es/EURdoc/JRC55629.pdf

[4] C. Christensen, C.W. Johnson \& M.B. Horn, Disrupting Class: How Disruptive Innovation Will Change the Way the World Learns, McGraw-Hill, New York, (2008).

[5] S. Ziegler, The (mis)education of Generation M, Routledge, Learning, Media and Technology, 32(1), pp.6981,Philadelphia, USA, (March 2007).

[6] M. Bugeja, Facing the Facebook,. The Chronicle of Higher Education, 52 (21), January 27th, p.C1, (October 2006), Retrieved January 6, 2011, Available on http://chronicle.com/article/Facing-the-Facebook/46904.

[7] B. Muirhead \& C. Juwah, Interactivity in computer-mediated college and university education: A recent review of the lite- 
rature, Educational Technology \& Society, 7 (1), pp.12-20, (2004).

[8] R.M. Carini, G.D. Kuh \& S.P. Klein, Student Engagement and Student Learning: Testing the Linkages, Research in Higher Education, 47 (1), pp.1-32, San Diego, USA, (April 2006).

[9] G. Attwell, The Personal Learning Environments - the future of eLearning? eLearning Papers, 2(1), (January 2007), Available

http://www.elearningeuropa.info/files/media/media11561.pdf

[10]A. Mikroyannidis, Toward a Social Semantic Web, IEEE Computer Society, Computer, 40 (11), pp.113-115, California, USA, (October 2007)

[11]T. Berners-Lee, Linked Data, W3C Design Issue, (July 2007)

Available http://www.w3.org/DesignIssues/LinkedData.html

[12] T. Berners-Lee, J. Hendler \& O. Lassila, The Semantic Web, Scientific American, 284(5), pp.34-43, (May 2001).

[13]D. Allemang \& J. Hendler, Semantic Web for the Working Ontologist: Effective Modeling in RDFS and OWL, Morgan Kaufmann, (2008).

[14]T. O'Reilly, What Is Web 2.0 - Design Patterns and Business Models for the Next Generation of Software, (2005), Available

http://www.oreillynet.com/pub/a/oreilly/tim/news/2005/09/30 /what-is-Web-20.html

[15]T. Gruber, Collective Knowledge Systems: Where the Social Web meets the Semantic Web, Elsevier Science Publisher, Journal of Web Semantics, 6(1), pp. 4-13, Amsterdam, The Netherlands, (February 2008).

[16] J. Jovanovic, D. Gasevic, C.Torniai, S.Bateman \& M.Hatala, The Social Semantic Web in Intelligent Learning Environments - State of the Art and Future Challenges, Interactive Learning Environments, Special Issue: Web 2.0 for interactive e-learning, 17(4), pp. 273-308, (December 2009).

[17]T. Tiropanis, H. Davis, D. Millard \& M. Weal, Semantic Technologies for Learning and Teaching in the Web 2.0 Era, IEEE Intelligent Systems, 24(6), pp.49-53, (2009)

[18]A. Westerski, S. R. Kruk, K. Samp, T. Woroniecki, F. Czaja, \& C. O’Nuallain., E-learning based on the social semantic information sources, Proceedings of $1^{\text {st }}$ Latin American conference on Learning Objects, Guayaquil, Ecuador, (2006).

[19]S. Auer, S. Dietzold, \& T. Riechert, OntoWiki - A Tool for Social, Semantic Collaboration. Proceedings of the 5th International Semantic Web Conference (ISWC 2006), pp. 736749, Athens, GA, USA, (2006).

[20] V. Zacharias, S. Braun \& A. Schmidt, Social Semantic Bookmarking with SOBOLEO, In San Murugesan (eds.): Handbook of Research on Web 2.0, 3.0 and X.0: Technologies, Business, and Social Applications, IGI Global, pp. 225241, (2009).

[21]S. Schaffert, D. Bischof, T. Bürger, A. Gruber, W. Hilzensauer \& S. Schaffert, Learning with Semantic Wikis, In Proceedings of the First Workshop on Semantic Wikis - From Wiki To Semantics, co-located with the 3rd Annual European Semantic Web Conference (ESWC2006), Budva, Montenegro, (2006), Available at: http://www.salzburgresearch.at/research/gfx/semantic_wiki_e learning.pdf

[22]S. Bajanki, K. Kaufhold, A. Le Bek, V. Dimitrova, L. Lau, R. O'Rourke \& A. Walker, Use of Semantics to Build an Academic Writing Community Environment, IOS Press, In Proceeding of the 14th International Conference on Artificial intelligence in Education, 200, pp. 357-364, Brighton, UK, (2009).
[23] J. Jovanovic, D. Gasevic, C. Brooks, V. Devedzic, M. Hatala T. Eap \& G. Richards, Using Semantic Web Technologies to Analyze Learning Content, IEEE Internet Computing, 11(5), pp. 45-53, (2007).

[24]F. Wild, F. Mödritscher \& S. Sigurdarson, Designing for Change : Mash-Up Personal Learning Environments, eLearning Papers, pp. 1-15, (July 2008), Available at: http://www.elearningeuropa.info/files/media/media15972.pdf

[25]M.A. Chatti, M. Jarke, Z. Wang \& M. Specht, SMashup Personal Learning Environments, In Proceedings of the Second International Workshop on Mashup Personal Learning Environments (MUPPLE09), ISSN 1613-0073, 506, Nice, France, (2009), http://ceur-ws.org/Vol-506/

[26] S. Sire, E. Bogdanov, D. Gillet, M. Palmer, F. Wild, Introducing qualitative dimensions to analyze the usefulness of Web 2.0 platforms as PLEs, International Journal of Technology Enhanced Learning, 3(1), pp. 40 - 60, (2011).

[27]Z. Jeremic, J. Jovanovic, D. Gasevic, Semantic Web Technologies for the Integration of Learning Tools and Contextaware Educational Services, In Proceedings of the 8th International Semantic Web Conference (ISWC 2009), Semantic Web in Use Track, pp. 860-875, Washington, DC, USA, (2009).

[28] M.A. Chatti, Anggraeni, M. Jarke, M. Specht \& K. Maillet, PLEM: a Web 2.0 driven Long Tail aggregator and filter for e-learning,. International Journal of Web Information Systems, 6(1), pp. 5-23, (2010).

[29]F. Modritscher \& F. Wild, Sharing Good Practice through Mash-Up Personal Learning Environments, Springer-Verlag, In Proceedings of the 8th International Conference on Advances in Web Based Learning (ICWL '009), pp. 245-254, Aachen, Germany, (2009),

[30]H. Drachsler \& D. Pecceu, Arts, T., Hutten, E., Rutledge, L. Van Rosmalen, P., Hummel, H.G.K., Koper, R.: ReMashed Recommendations for Mash-Up Personal Learning Environments. In: Cress, U., Dimitrova, V., Specht, M. (eds.): Learning in the Synergy of Multiple Disciplines, EC-TEL 2009, Lecture Notes in Computer Science, Vol. 5794, SpringerVerlag, Nice, France, (2009).

[31]E. Bogdanov, S. El Helou, D. Gillet, C. Salzmann \& S. Sire, Graaasp: a web 2.0 research platform for contextual recommendation with aggregated data., Proceedings of the 28th International Conference on Human Factors in Computing Systems, CHI 2010, Extended Abstracts Volume, pp. 3523-3528, Atlanta, Georgia, USA, (2010).

[32]C. Clarke, A Resource List Management Tool for Undergraduate Students based on Linked Open Data Priciples, Springer-Verlag, Proceedings of the 6th European Semantic Web Conference (ESWC2009), pp. 697-707, Heraklion, Crete, Greece ,(2009).

[33]F. Abel, N. Henze, D. Krause \& M. Kriesell, Semantic Enhancement of Social Tagging Systems. In V. Devedzic \& D. Gasevic (eds.): Annals of Information Systems (Special Issue on Semantic Web and Web 2.0), 6(1), pp. 25-54, (2010).

[34]I. Marenzi, R. Kupetz, W. Nejdl \& S. Zerr, Supporting Active Learning in CLIL through Collaborative Search, In X.Luo, M. Spaniol, L. Wang, Q.Li, W. Nejdl \& W. Zhang (eds.): Advances in Web-Based Learning, Proceedings of International Conference on Advances in Web-Based Learning, ICWL 2010, Lecture Notes in Computer Science, SpringerVerlag, pp.200-209, Shanghai, China, (December, 2010).

[35]J. O'Connell, Creative Web 2.0 learning, A talk given at Christian Teacher Librarians Association conference, Sydney, (23 May 2007), Available at: http :// www.slideshare.net/heyjudeonline/creative-web-20-learning 
[36]S. Downes, Learning networks in practice, In D. Ley (Ed.) Emerging technologies for learning, BECTA, 2, pp. 19-27, (2007), Available at: http://partners.becta.org.uk/page_documents/research/emergi ng_technologies07_chapter2.pdf

[37]T.D. Anderson \& D.R. Garrison, Learning in a networked world: New roles and responsibilities, In C.C. Gibson (ed), Distance learning in higher education: Institutional responses for quality outcomes. Madison, WI, Atwood Publishing, 1998, pp. 97-112, (1998)

[38] J. Jovanovic, D. Gasevic, C. Torniai \& V. Devedzic, Using 9Semantic Web Technologies to Provide Contextualized Feedback to Instructors, In Dicheva, D., Mizoguchi, R., Greer, J., (Eds.) Ontologies and Semantic Web for eLearning, IOS Press, Amsterdam, The Netherlands, (2009).

[39] J. Jovanovic, C. Knight, D. Gasevic \& G. Richards, Ontologies for Effective Use of Context in e-Learning Settings. Educational Technology \& Society, 10(3), pp. 47-59, (2007).

[40]F. Zablith, M. Fernandez \& M. Rowe, The OU Linked Open Data: production and consumption. In Proceedings of Linked Learning 2011: 1st International Workshop on eLearning Approaches for the Linked Data Age, Proceeding 8th Extended Semantic Web Conference (ESWC2011), CEUR 717,, Heraklion, Greece, (May 2011). Available at:http://ceurws.org/Vol-717/paper1.pdf

[41]L. Johnson, A. Levine, R. Smith \& S. Stone, The 2010 Horizon Report, The New Media Consortium, Austin, Texas, USA, (2010), Available at: http://www.nmc.org/pdf/2010Horizon-Report.pdf

[42] M. Sicilia, H. Ebner, S. Sanchez-Alonso, F. Alvarez, A. Abián \& E. Garcia-Barriocanal, Navigating learning resources through linked data: a preliminary report on the redesign of Organic.Edunet. In Proceedings of Linked Learning 2011: 1st International Workshop on eLearning Approaches for the Linked Data Age at the 8th Extended Semantic Web Conference (ESWC2011), Heraklion, Greece (2011), Available at: http://ceur-ws.org/Vol-717/paper10.pdf

[43]E. Kaldoudi, N. Dovrolis, D. Giordano \& S. Dietze, Educational Resources as Social Objects in Semantic Social Networks. In Proceedings of Linked Learning 2011: 1st International Workshop on eLearning Approaches for the Linked Data Age at the 8th Extended Semantic Web Conference (ESWC2011), Heraklion, Greece (2011), Available at: http://ceur-ws.org/Vol-717/paper11.pdf

[44]F. Carmagnola, F. Osborne \& I. Torre, User data distributed on the social web: how to identify users on different social systems and collecting data about them. In Proceedings of the 1st International Workshop on Information Heterogeneity and Fusion in Recommender Systems (HetRec '10). ACM, pp. 9-15, New York, NY, USA, (2010).

[45] J. Vassileva, Distributed User Modelling for Universal Information Access, In C. Stephanidis (Ed.), Universal Access in Human - Computer Interaction (UAHCI), Proceedings of the 9th International Conference on Human-Computer Interaction, Lawrence Erlbaum: Mahwah, 3, pp. 122-126, New Orleans, USA, (2001).

[46]P. Brusilovsky, S.A. Sosnovsky \& O. Shcherbinin, User Modeling in a Distributed E-Learning Architecture, Proceedings of the 10th International Conference, UM 2005, pp. 387391 pp. 387-391, Edinburgh, Scotland, UK, (July 2005),

[47]Dolog, P. \& Schäfer, M. (2005). A framework for browsing, manipulating and maintaining interoperable learner profiles. In L. AArdissono, P. Brna \& A.Mitrovic (Eds.), User Modeling 2005, In Proceedings of the 10th International Conference on User Modeling, Lecture Notes in Computer Science, Edinburgh, Scotland, pp. 387-391 (2005).
[48]D. Heckmann, T. Schwartz, B. Brandherm \& A. Kröner Decentralized User Modeling with UserML and GUMO, In P.Dolog \& J.Vassileva (Eds.), Decentralized, Agent Based and Social Approaches to User Modeling, (DASUM 2005), pp. 61-65, Edinburgh, Scotland, (2005).

[49] M. Rowe \& F. Ciravegna, Getting to Me - Exporting Semantic Social Network from Facebook, , In J. Breslin, U. Bojars, A. Passant \& S. Fernandez, Proceedings of the First Social Data on the Web Workshop, International Semantic Web Conference, CEUR Workshop Proceedings, ISSN 16130073, 405, Karlsruhe, Germany, (October 2008), Available at: http://CEUR-WS.org/Vol-405/paper7.pdf

[50]M. Stankovic, Modeling Online Presence, In J. Breslin, U. Bojars, A. Passant \& S. Fernandez, Proceedings of the First Social Data on the Web Workshop, CEUR Workshop Proceedings, ISSN 1613-0073, 405, Karlsruhe, Germany, (October 2008), Available at: CEUR-WS.org/Vol-405/paper9.pdf

[51]J. Jovanovic, D. Gasevic, M. Stankovic, Z. Jeremic \& M. Siadaty, Online Presence in Adaptive Learning on the Social Semantic Web, In Proceedings of the 1st IEEE International Conference on Social Computing - Workshops (Workshop on Social Computing in Education), Vancouver, pp. 891-896, BC, Canada, (2009).

[52] S.R. Kruk, S. Decker, A. Gzella, S. Grzonkowski \& B. McDaniel, Social semantic collaborative filtering for digital libraries, Journal of Digital Information, Special Issue on Personalization, (2006).

[53] S.R. Kruk, FOAF-Realm - control your friends' access to the resource. In Proceedings of the 1st Workshop on Friend of a Friend, Social Networking and the (Semantic) Web (FOAF Galway), pp.1-9, Galway, Ireland (September 2004), Available at: http://library.deri.ie/resource/dbe66985

[54]P. Bonatti, C. Duma, B.E. Fuchs, W. Nejdl, D. Olmedilla, J. Peer, \& N. Shahmehri, Semantic Web Policies - A Discussion of Requirements and Research Issues. Lecture Notes in Computer Science, In Proceedings of the 3rd European Semantic Web Conference (ESWC 2006), Springer, 4011,pp. 712-724, Budva, Montenegro, (June 2006).

[55]J.L. De Coi, P. Kärger, A.W. Koesling, \& D. Olmedilla, Control your elearning environment: Exploiting policies in an open infrastructure for lifelong learning, in IEEE Transactions on Learning Technologies, 1(1), pp 88-102, (March 2008).

[56]S. Braun, A. Schmidt \& C. Hentschel, Semantic Desktop Systems for Context Awareness - Requirements and Architectural Implications. In 1st Workshop on Architecture, Design, and Implementation of the Semantic Desktop, collocated with the 4th European Semantic Web Conference (ESWC2007), Innsbruck, Austria, (2007).

[57] M. Siadaty, C. Torniai, D. Gasevic, J. Jovanovic, T. Eap, M. Hatala, m-LOCO: An Ontology-based Framework for Context-Aware Mobile Learning. Proceedings of the 6th International Workshop on Ontologies and Semantic Web for Intelligent Educational Systems collocated with the 9th International Conference on Intelligent Tutoring Systems, Montreal, Canada, (2008).

[58]A. Schmidt, Ontology-Based User Context Management: The Challenges of Dynamics and Imperfection, In R. Meersman \& Z. Tahiri (Eds.), On the Move to Meaningful Internet Systems 2006: CoopIS, DOA, GADA, and ODBASE, Lecture Notes in Computer Science 4275, Springer, pp. 995-1011, (2006).

[59]C. Ghidini, V. Pammer, P. Scheir, L. Serafini \& S. Lindstaedt, APOSDLE: Learn@work with semantic web technology, In Proceedings of The Innovation Conference for Knowledge Management, New Media Technologies and Se- 
mantic Technologies (I-Know '07), pp.262-269 Graz, Austria, (September 2007).

[60] IntelLEO D3.2, IntelLEO - Intelligent Learning Extended Organisation, Deliverable D3.2 Implementation Framework First version (WP 300), 7th Framework Program Theme 3, Project no. FP7-ICT-231590, (2010).

[61]S. Dietze, A. Gugliotta \& J. Domingue, A Semantic Web Service oriented Framework for adaptive Learning Environments, In E.Franconi, M. Kifer \& W. May (Eds.), The Semantic Web: Research and Applications, Proceedings of 4th European Semantic Web Conference (ESWC 2007), Lecture Notes in Computer Science, Springer-Verlag, 4519/2007, pp. 701-715, Innsbruck, Austria, (June 2007).

[62]S. Harris \& A. Seaborne, SPARQL 1.1 Query Language, W3C Working Draft, (October 2010), Available at: http://www.w3.org/TR/sparql11-query/

[63]D. Degler, Semantic Web Interface Design: Opportunities and Techniques. Presentation at Semantic Technologies 2010 Conference, San Francisco, USA, (June 2010), Available at: http://designforcontext.com/publications/dd_design_semtech _2010-06-22.pdf

[64]C. Yeung, I. Liccardi, K. Lu, O. Seneviratne \& T. BernersLee, Decentralization: The Future of Online Social Networking, W3C Workshop on the Future of Social Networking, (2009), Available http://www.w3.org/2008/09/msnws/papers/decentralization.p $\mathrm{df}$

[65]B.J. Zimmerman, Becoming a self-regulated learner: An overview, In Theory into Practice, Taylor \& Francis, Ltd. 41(2), pp. 64-72, College of Education, The Ohio State University, USA (2002).

[66] M. Osterloch, Human resources management and knowledge creation, In K. Ichijo \& I. Nonaka (Eds.) Knowledge creation and management. New challenges for managers. Oxford University Press, pp. 158-175, (2007)

[67]Z. Jeremic, J. Jovanovic \& D. Gasevic, Towards a Semanticrich Collaborative Environment for Learning Software Patterns, In Proceedings of the 3rd European Conference on Technology Enhanced Learning (EC-TEL2008), SpringerVerlag, Maastricht, The Netherlands, pp.155-166, (2008).

[68]G. Kearsley \& B. Shneiderman, Engagement theory: A framework for technology-based learning and teaching, Educational Technology, 38(5), pp.20-23, (1999), Available at http://home.sprynet.com/ gkearsley/engage.htm

[69] M. Jazayeri, The Education of a Software Engineer, In the Proceedings of the $19^{\text {th }}$ IEEE International Conference on Automated software engineering, IEEE Computer Society, pp.18-xxvii, Washington, DC, USA, (2004).
[70]L. Dodds \& I. Davis, Linked Data Patterns, (2010), Available at: http://patterns.dataincubator.org/book/

[71]S. Henninger, A Framework for Flexible and Executable Usability Patterns Standards, In Proceedings of the $31^{\text {st }}$ IEEE Software Engineering Workshop (SEW '07), IEEE Computer Society, pp. 23-34, Washington, DC, USA, (2007)..

[72]Z. Jeremic, J. Jovanovic \& D. Gasevic, An Environment for Project-based Collaborative Learning of Software Design Patterns, International Journal on Engineering Education, 27(1), pp. 41-51, (2011).

[73]J. C. Richardson \& K. Swan, Examining social presence in online courses in relation to students' perceived learning and satisfaction, Journal of Asynchronous Learning Networks,.7(1), pp. 68-88, (February 2003).

[74]C.D. Manning, P. Raghavan, H. Schütze, Introduction to Information Retrieval, Cambridge University Press, (2008).

[75]D. Gasevic, A. Zouaq, C. Torniai, J. Jovanovic \& M. Hatala, An Approach to Folksonomy-based Ontology Maintenance for Learning Environments, IEEE Transactions on Learning Technologies, IEEE Computer Society, 99(1), Los Alamitos, CA, USA, (2011).

[76]S. Bateman, R. Farzan, P. Brusilovsky \& G. McCalla. OATS The Open Annotation and Tagging System. In the Proceedings of the Third Annual International Scientific Conference of the Learning Object Repository Research Network, Montreal, Canada (November 2006).

[77]J. Frechtling, H. Frierson, S. Hood \& G. Hughes, The 2002 User-Friendly Handbook for Project Evaluation, NSF 02-057, National Science Foundation, Arlington, VA, USA http://www.nsf.gov/pubs/2002/nsf02057/

[78] V. Dimitrova, Social Linked Data and Experiential Learning: Opportunities and Challenges, Keynote speech at Linked Learning 2011: 1st International Workshop on eLearning Approaches for the Linked Data Age, 8th Extended Semantic Web Conference (ESWC2011), Heraklion, Greece, (2011), Slides Available http://stefandietze.files.wordpress.com/2011/05/ll-eswc2011-vania-last.pdf

[79]D.R. Garrison, T. Anderson \& W. Archer, Critical inquiry in a text-based environment: Computer conferencing in higher education, The Internet and Higher Education, 2(2-3), pp.87105, (2000).

[80]P.R. Pintrich, C.A. Wolters \& G.P. Baxter, Assessing metacognition and self-regulated learning, G. Schraw, J.C. Impara (Eds.), Issues in the measurement of metacognition, pp. 4397, Lincoln, NE, Buros Institute of Mental Measurement, (2000). 


\section{Appendix}

Table 1 An overview of the state-of-the-practice in social software and SSW tools/services, and their contribution to the interactivity of online learning environments.

\begin{tabular}{|c|c|c|c|}
\hline $\begin{array}{l}\text { Interactivity } \\
\text { types }\end{array}$ & Tool types & Social software tools & Social Semantic Web tools \\
\hline \multirow[t]{4}{*}{$\begin{array}{l}\text { Interaction } \\
\text { among members } \\
\text { of an online } \\
\text { learning com- } \\
\text { munity (student- } \\
\text { student, student- } \\
\text { teacher, teacher- } \\
\text { teacher) }\end{array}$} & $\begin{array}{l}\text { Social networking } \\
\text { tools: } \\
\text { (online discussions, } \\
\text { content sharing, } \\
\text { tagging, } \\
\text { commenting, } \\
\text { content/peers } \\
\text { recommendations) }\end{array}$ & $\begin{array}{l}\text { Special focused learning groups within general } \\
\text { online social networks, like Facebook, Orkut, } \\
\text { YouTube } \\
\text { Specialized online social networks: } \\
\text { - for students: CollegeRuled } \\
\text { (http://collegeruled.com/), NoteMesh } \\
\text { (http://www.notemesh.com/) } \\
\text { - for teachers: Curriki (http://www.curriki.org/), } \\
\text { Connexions (http://cnx.org/), } \\
\text { EdTechTalk (http://www.edtechtalk.com/) } \\
\text { - for students and teachers: } \\
\text { Mixxer (http://www.language-exchanges.org/), } \\
\text { BuddySchool (http://www.buddyschool.com/) } \\
\text { VoiceThread (http://www.voicethread.com) }\end{array}$ & $\begin{array}{l}\text { Special focused learning groups within gen- } \\
\text { eral online social semantic networks, like } \\
\text { Social Grail } \\
\text { (http://www.assembla.com/spaces/social- } \\
\text { grail) } \\
\text { GroupMe (http://groupme.org/GroupMe/) } \\
\text { Learning-focused social semantic network: } \\
\text { Metamorphosis+ } \\
\text { (http://metamorphosis.med.duth.gr/) }\end{array}$ \\
\hline & $\begin{array}{l}\text { Collaborative } \\
\text { authoring tools }\end{array}$ & $\begin{array}{l}\text { Online office tools: } \\
\text { - Google Docs (http://docs.google.com/), } \\
\text { - Zoho (http://www.zoho.com) } \\
\text { Wiki tools, like Wikispaces } \\
\text { (http://www.wikispaces.com/), } \\
\text { Wetpaint (www.wetpaint.com/) }\end{array}$ & $\begin{array}{l}\text { Semantic Desktop office tools } \\
\text { KOffice (http://www.koffice.org/) } \\
\text { Semantic wikis, like } \\
\text { Semantic Media Wiki (http://semantic- } \\
\text { mediawiki.org/), IkeWiki } \\
\text { (http://ikewiki.salzburgresearch.at/) }\end{array}$ \\
\hline & $\begin{array}{l}\text { Expression and } \\
\text { exchange } \\
\text { of opinions }\end{array}$ & $\begin{array}{l}\text { Blogging tools, like } \\
\text { Blogger (http://www.blogger.com/), } \\
\text { Wetpaint }\end{array}$ & $\begin{array}{l}\text { Semantically enhanced blogging tools, like } \\
\text { Wordpress (http://wordpress.org/ })^{52} \text {, } \\
\text { Livejournal (www.livejournal.com/ })^{53} \text {, or } \\
\text { any blog powered by Zemanta } \\
\text { (http://www.zemanta.com/) }\end{array}$ \\
\hline & Reviews and ratings & $\begin{array}{l}\text { Education focused: } \\
\text { Rate My Professors (www.ratemyprofessors.com/) }\end{array}$ & $\begin{array}{l}\text { General purpose: } \\
\text { Revyu (http://revyu.com/) }\end{array}$ \\
\hline \multirow{5}{*}{$\begin{array}{l}\text { Interactions with } \\
\text { learning content } \\
\text { (student-content, } \\
\text { teacher-content) }\end{array}$} & $\begin{array}{l}\text { Social bookmarking } \\
\text { and annotation tools }\end{array}$ & $\begin{array}{l}\text { delicious.com, diigo (http://www.diigo.com), } \\
\text { StumbleUpon (http://www.stumbleupon.com/) }\end{array}$ & $\begin{array}{l}\text { Faviki (http://www.faviki.com) } \\
\text { Bibsonomy (http://www.bibsonomy.org/) }\end{array}$ \\
\hline & $\begin{array}{l}\text { Data visualization } \\
\text { and exploration tools }\end{array}$ & $\begin{array}{l}\text { ManyEyes } \\
\text { (www.many-eyes.com) } \\
\text { mSpace (http://mspace.fm/) } \\
\text { Choosel (http://code.google.com/p/choosel/) }\end{array}$ & $\begin{array}{l}\text { Exhibit (http://simile.mit.edu/exhibit/) } \\
\text { Freebase Parallax } \\
\text { (http://mqlx.com/ david/parallax/), } \\
\text { Potluck (http://simile.mit.edu/potluck/) } \\
\text { RKBExplorer } \\
\text { (http://www.rkbexplorer.com/explorer/) }\end{array}$ \\
\hline & $\begin{array}{l}\text { Tools for creating } \\
\text { mash-ups }\end{array}$ & $\begin{array}{l}\text { NeedleBase (http://www.needlebase.com/) } \\
\text { Google Fusion Tables } \\
\text { (http://www.google.com/fusiontables) } \\
\text { Personal Dashboards, e.g., } \\
\text { http://www.google.com/ig, } \\
\text { http://www.pageflakes.com/, } \\
\text { http://www.netvibes.com/ }\end{array}$ & $\begin{array}{l}\text { Potluck (http://simile.mit.edu/potluck/) } \\
\text { Sigma (http://sig.ma/) } \\
\text { Paggr (http://paggr.com/) }\end{array}$ \\
\hline & $\begin{array}{l}\text { Services providing } \\
\text { data for mash-ups }\end{array}$ & $\begin{array}{l}\text { Socrata (http://www.socrata.com/), } \\
\text { Factual (http://www.factual.com/), } \\
\text { Infochimps (http://www.infochimps.com/) }\end{array}$ & $\begin{array}{l}\text { DBpedia (http://dbpedia.org/), } \\
\text { and the continuously growing Linked Open } \\
\text { Data Cloud } \\
\text { (http://richard.cyganiak.de/2007/10/lod/) }\end{array}$ \\
\hline & $\begin{array}{l}\text { Tools for manipulating } \\
\text { RSS feeds }\end{array}$ & Yahoo! Pipes (http://pipes.yahoo.com/) & DERI Pipes (http://pipes.deri.org/) \\
\hline
\end{tabular}


